\title{
Cancer: Tumor Iron Metabolism, Mitochondrial Dysfunction and Tumor Immunosuppression; “A Tight Partnership-Was Warburg Correct?”
}

\author{
Robert L. Elliott, Jonathan F. Head
}

Elliott-Barnett-Head Breast Cancer Research and Treatment Center, Baton Rouge, USA.

Email: relliott@eehbreastca.com

Received May 25 ${ }^{\text {th }}, 2012$; revised June $26^{\text {th }}, 2012$; accepted July $31^{\text {st }}, 2012$

\begin{abstract}
Over the last 30 years there have been numerous worldwide investigators involved in cancer research. Billions of dollars have been spent on drug development and cancer research; however, with all of the new agents and modalities of treatment, we have honestly not significantly improved the overall survival of the Stage IV cancer patient. There is and will not be a magic bullet treatment, thus the extensive title of this paper. We are convinced that unless we use multiple innovative therapies in combination with conventional treatment, we will never truly defeat this disease. We have attempted to address this problem by presenting in detail some of these complex mechanisms involved in tumorigenesis, progression, escape, and metastasis. Most investigators have their own special area of interest, but if we are to conquer this scourge, we must develop an extensive, multifaceted, comprehensive approach. Hopefully this article will contribute to awareness and further insight into this very serious and complicated problem, so we can improve quality of life and improve the survival of the Stage IV cancer patient.
\end{abstract}

Keywords: Tumor Iron Metabolism; Mitochondrial Iron Metabolism; Mitochondrial Dysfunction; Tumor Immunosuppression; Hypoxia Inducible Factor; Pseudohypoxia

\section{Introduction}

Cancer is a very complex disease that can involve any organ and tissue of the human body. The evolution of cancer involves numerous complex molecular events and is probably unique and different in each individual patient. Each cancer has unique characteristics, such as causation, tumor biology, methods of progression, and predicted response to therapy. However, all cancers have certain similar mechanisms that control growth, progression, metastasis, and survival.

It is impossible and too complex to address and discuss all cancer growth mechanisms in one communication. Therefore, we decided to present three important partners involved in the molecular events of tumorigenesis. These three partners are intertwined, tightly integrated and complement each other. The roles they play in tumorigenesis, cancer biology, growth and progression are synergistic, and this synergism brings into play many other molecular mechanisms that are involved in the support of cancer growth, progression, metastasis, and ultimately death of the patient.

After nearly 40 years of research and treating breast cancer patients, we have become convinced that the three major players in tumorigenesis are: 1) Tumor iron metabolism; 2) Mitochondrial dysfunction; and 3) Tumor immune suppression. One and two may be almost one and the same and just different phases of the tumorigenic process. All three players are integrated and supportive of the other. The many events they control in cancer may be sequential, but many of the molecular events probably occur simultaneously. We suspect that an initial event in tumorigenesis may be some slight dysfunction in iron metabolism, and this will be supported by much of the following discussion.

We will attempt to discuss each partner's role separately, and also show their integrated complimentary relationship. This presentation will be supported by much of our personal research as well as the research of other investigators. This will be a difficult task because of the many molecular events; and it is impossible to determine which comes first, "the chicken or the egg"?

We could not start this journey without recognizing the tremendous contributions of scientist like Ehrlich and Warburg. We are amazed at their work and observations done in their era, especially with the technology and equipment then available. They were tremendous observers 
and innovators with an uncanny imaginative intellect. The foundations of their contributions have stood the test of time and are true today. This is a strong testament to their research; and new research by present investigators are confirming and expanding their ideas. This communication is a tribute to their amazing and important contributions.

\section{Iron Metabolism}

\subsection{Tumor Iron Metabolism}

Abnormal iron metabolism may be the main culprit and player in tumorigenesis, as it is definitely involved in tumor metabolism and cancer mitochondrial dysfunction. Iron also plays a significant role in tumor immunosuppression. Thus, playing a role in the mechanisms and function of all three partners in tumorigenesis.

Iron $(\mathrm{Fe})$ is an essential metal vital for living cells [1$3]$. It is required by a large number of heme and nonheme enzymes and proteins, which have essential functions in oxygen transport and oxidative phosphorylation [4]. Iron is a cofactor for ribonucleotide reductase, an enzyme that converts ribonucleotides to deoxyribonucleotides and thus is a key enzyme in DNA synthesis, and it requires a continuous supply of iron to maintain its activity $[5,6]$. Therefore, iron is directly associated with cell proliferation.

Transferrin (TF), a bilobed glycoprotein is the chief iron transport protein in mammalian blood. It has a molecular weight of about 78,000, and it transports iron from sites of absorption and storage to sites of iron utilization [7]. Iron bound TF specifically interacts with a cell surface transferrin receptor (TFR1) that promotes the transport of iron across the cell membrane by endocytosis. The entire TF-TFR1 complex is internalized and then the $\mathrm{pH}$ within the endosome decreases due to a proton pump in the endosomal membrane. The acidic environment is around $\mathrm{pH} 5.5$ and allows $\mathrm{Fe}^{3+}$ atoms to disassociate from the complex [8]. The ferric $\left(\mathrm{Fe}^{3+}\right)$ is reduced to the ferrous state by a ferrireductase and is then transported out of the endosome into the cytoplasm by the divalent metal transporter-1 (DMT1). The apo-TF-TFR1 complex is then recycled back to the cell surface and apo-transferrin is released into the bloodstream (Figure 1) [9].

The transferrin receptor (TFR) was purified and characterized in 1979 [10,11]. Lazarus and Baines [12] documented that transferrin receptors were present on malignant and proliferating cells in high numbers; while Shindleman et al. [13] demonstrated the presence of TFRs in breast carcinoma by a sophisticated cytochemical technique. Our earlier work in rats with malignant tumors confirmed the importance of iron bound transfer-

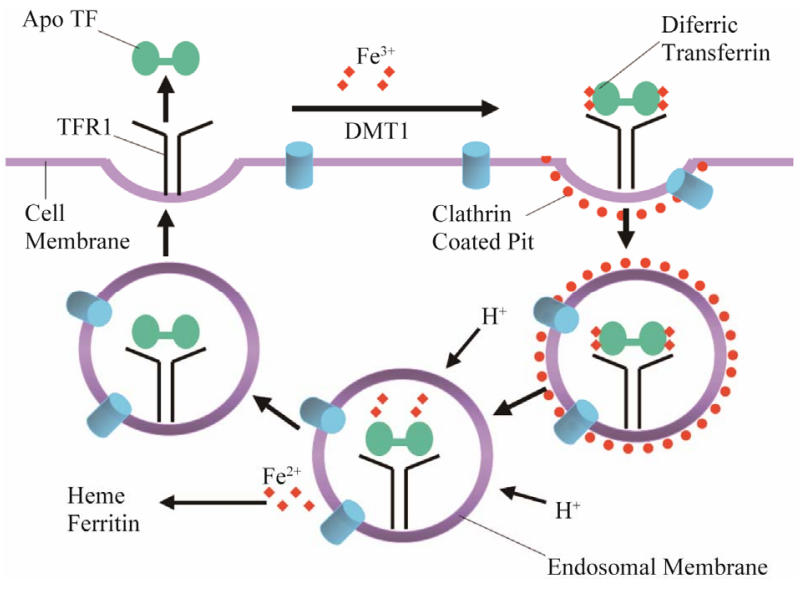

Figure 1. The transferrin cycle and the transferrin receptor 1-mediated cellular iron uptake. Diferric transferrin (holotransferrin) binds to transferrin receptor 1 at the cell surface. The complex is endocytosed in clathrin coated pits, and the endosome is then acidified by action of a proton pump. Iron is released from transferrin and transported out of the endosome via the DMT1 (divalent metal transporter 1) into the cytosol labile iron pool. Apotransferrin and transferrin receptor 1 return to the cell surface where they dissociate at neutral $\mathrm{pH}$ and are available for another iron cycle. Intracellular iron is used by ribonucleotide reductase for DNA synthesis, incorporated into heme or stored in ferritin.

rin in malignancy [14]. It was revealed by electron paramagnetic studies on serum and tumor tissue, low serum levels and very high tumor tissue levels of iron bound transferrin during the peak of tumor growth. Importantly when the rat lymphosarcoma was inhibited by treatment with cis-dichloro-diamine platinum (II), the serum and tissue iron bound transferrin rose and dropped respecttively [15].

In 1993, we [16] reported on the role of iron metabolism in breast carcinoma. This was an extensive cytochemical, tissue culture, and ultrastructural study. This study demonstrated that the iron storage protein ferritin was increased and located in the cytoplasm of the tumor cells. It also confirmed that transferrin could be used as a carrier to target toxic therapy selectively to tumor tissue. There was strong evidence that our platinum transferrin complex (MPTC-63) decreases metallothionein synthesis, resulting in a decrease of superoxide dismutase activity. The decrease in superoxide dismutase activity within the cell results in increased susceptibility of the cell to superoxide anions and other free radicals. Pre-treatment with MPTC-63 followed by drugs known to generate free radicals show a synergistic response. In 1988, we reported a preliminary evaluation of a platinum transferrin complex MPTC-63 as a potential nontoxic treatment for breast cancer [17]. This was an in vivo study in the human and Fischer rat. This study confirmed the efficacy of 
the complex and proved it was targeted to tumor tissue and not to normal tissue (Figure 2). This was one of the first demonstrations of selectively delivering cytotoxic biotherapy to tumor cells effectively without systemic toxicity for the host.

Shpyleva and Tryndyak et al. [18] have recently reported on the role of ferritin alterations in human breast cancer cells. They showed that a downregulation of ferritin was associated with an increased sensitivity of MDA-MB-231 cells to the chemotherapeutic agent doxorubicin. This suggested that perturbation in ferritin levels are associated with the progression of breast cancer toward a more malignant phenotype. It has also clearly indicated the link between dysregulation in intracellular iron metabolism and the aggressiveness of breast cancer. Increased intracellular ferritin levels may be a critical defense mechanism in cancer cells to protect against ironinduced toxicity providing a more favorable environment for progression of cells to a more malignant phenotype. Alkhateeb and Connor [19] have shown in a poster presentation at the 2011 AACR meeting that ferritin binds cancer cells and tissue, and it promotes proliferation independently of iron content. We believe that ferritin may also be an intracellular source of iron for DNA synthesis in cancer cells.

Cheng and Zak [20] have described in detail a sophisticated study on the structure of the human transferrin receptor-transferrin complex (TFR-TF). Although much is understood of the transferrin endocytic cycle, little has been uncovered on the molecular events underlying the formation of the receptor-transferrin complex. By using cryo-electron microscopy, they produced a density map of the TFR-TF complex at subnanometer resolution. An atomic model was obtained by fitting crystal structures of diferric $\mathrm{TF}$ and the receptor ectodomain into the map. This showed that the TF N-lobe is sandwiched between the membrane and the TFR ectodomain and the C-lobe abuts the receptor helical domain. When TF binds the

Tissue Concentration of Platinum in Breast Cancer

Patients Treated with Cisplatin Transferrin Complex

\begin{tabular}{|c|c|c|}
\hline Patient\# & $\begin{array}{c}\text { Normal Breast } \\
\text { microgram/gm }\end{array}$ & $\begin{array}{c}\text { Tumor } \\
\text { microgram/gm }\end{array}$ \\
\hline 4 & ------ & 1.390 \\
\hline 9 & 0.178 & 0.478 \\
\hline 12 & 0.145 & 0.450 \\
\hline
\end{tabular}

Figure 2. Shows that platinum was concentrated at higher levels in breast cancer tissue than normal breast tissue. This confirmed that the cisplatin transferrin complex was targeted to the tumor tissue. receptor, its N-lobe moves about 9A with respect to the C-lobe. The structure of the TFR-TF complex explains for known differences in the iron-release properties of free and receptor bound TF.

The Penichet group from UCLA have done a great job in reporting on the role of the TFR in cancer [21,22]. They discuss the elevated levels of the TFR in malignancies, its relevance in cancer, and that the extracellular accessibility of this molecule make it an excellent antigen for the treatment of cancer using antibodies [21]. They show that the TFR can be targeted by monoclonal antibodies specific for the extracellular domain of the receptor. These cytotoxic antibodies targeting the TFR inhibit cell growth, and also induce apoptosis in the targeted malignant cells [21]. In Part II of their work on targeting the TFR, they discuss in detail targeted delivery of many different therapeutic agents into cancer cells [22]. Their work confirms the rationale of targeting the TFR for cancer treatment. Conventional chemotherapeutic drugs frequently fail to eliminate the tumor, and when effective, systemic toxicity is often severe. These problems are overcome by designing targeted therapies. This can be done by binding or conjugating cytotoxic agents to TF or directing antibodies and antibody complexes to the TFR. Daniels and Ortiz-Sanchez et al. [23] of the Penichet group have shown the tremendous importance of the TFR in B-cell malignancies. They showed in vitro and in vivo efficacy of an antibody multifaceted approach targeting the human TFR for the treatment of B-cell malignancies.

Habashy, Powe, and Staka et al. [24] have shown that the TFR (CD71) is a marker of poor prognosis in breast cancer and can predict response to Tamoxifen. The CD71 protein expression was evaluated in a series of patients with invasive breast cancer using tissue microarrays. The results demonstrated a marked elevation of TFR (CD71) in all cell models of acquired resistance. CD71 by multivariate analysis was found to be an independent prognostic indicator in the ER (+) (estrogen receptor positive) cohort of patients. We [25] have shown marked inhibittion in the growth of human breast carcinoma cells by an antisense oligonucleotide targeted to the TFR gene, again supporting the role of cellular iron import mechanisms in cellular cancer metabolism.

We later reported that the manipulation of iron transporter genes results in the suppression of human and mouse mammary adenocarcinomas [26]. Besides the TFRs, other iron importers, including SLC11A2 (also known as DMT1, NRAMP2, and DCT1) have been identified in the tissues where major iron uptake occurs, including duodenal enterocytes, placental trophoblast, macrophages, and hepatocytes. SLC11A2 transports iron into cells, which makes it a likely candidate for transfer- 
rin-independent iron uptake $[27,28]$. Some cells also express iron exporter genes and have the iron exporter ferroportin. This exporter is essential for iron homeostasis and transports iron out of cells. We found that iron increased the expression of SLC11A2 mRNA in MCF-12. A normal epithelium and MCF-7 cancer cells, but the MCF-7 cancer cells had significantly higher levels of SLC11A2 than the MCF-12A normal cells. Interestingly expression of the iron exporter gene SLC40A1 was lost in the MCF-7 cells and reflects an increased demand for bioavailable iron and a high turnover in breast cancer cells (Figure 3) [26]. The results of our study on iron transporter genes demonstrated that human breast cancer cells obtain their iron requirements through the upregulation of the expression of iron importer genes TFR and SLC11A2, with downregulation of the iron exporter gene SLC40A1 (Figure 4). We concluded from this study that complete blocking of all iron importer gene pathways would produce maximum iron depletion and better tumor

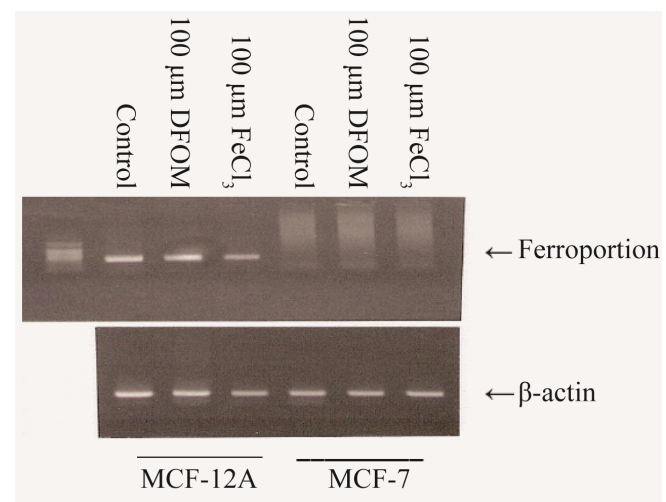

Figure 3. Electrophoresis of RT-PCR products for analysis of ferroportin mRNA expression in MCF-7 human breast cancer cells and MCF-12A normal human mammary epithelia. The MCF-7 cancer cells do not express ferroportin.

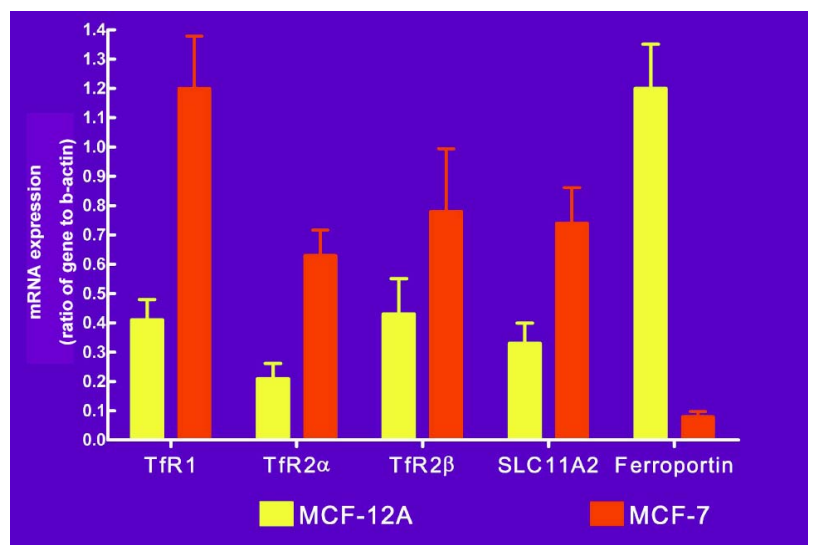

Figure 4. Shows that mRNA expression of all iron importer genes are elevated in the MCF-7 cancer cells over the MCF-12A normal cells, while the MCF-7 cancer cells have lost the expression of the iron exporter ferroportin. inhibition. In addition, increasing expression of the iron exporter gene SLC40A1 by transfection of cancer cells with a plasmid containing the SLC40A1 gene could enhance the effect of iron deprivation of cancer cells, thus inhibiting their proliferation. Therefore, depleting iron through a combination of reduced uptake and increased export might become a viable method of cancer therapy.

We have also shown the inhibitory effect of deferoxamine mesylate and low iron diet on the $13762 \mathrm{NF}$ rat mammary adenocarcinoma confirming the need for iron in cell replication [27]. Another study by us [28] demonstrated the induction of apoptosis by iron depletion in the human breast cancer MCF-7 cell line and the 13762 NF rat mammary adenocarcinoma in vivo. In another study [29] we discussed in detail antineoplastic drugs that interfered with iron metabolism in cancer cells, and showed that doxorubicin drug resistance could be reversed by a doxorubicin transferrin conjugate (Figures 5 and 6). All these studies emphasize the importance of iron in the growth and proliferation of cancer cells; and supports the concept of attacking and disrupting tumor iron

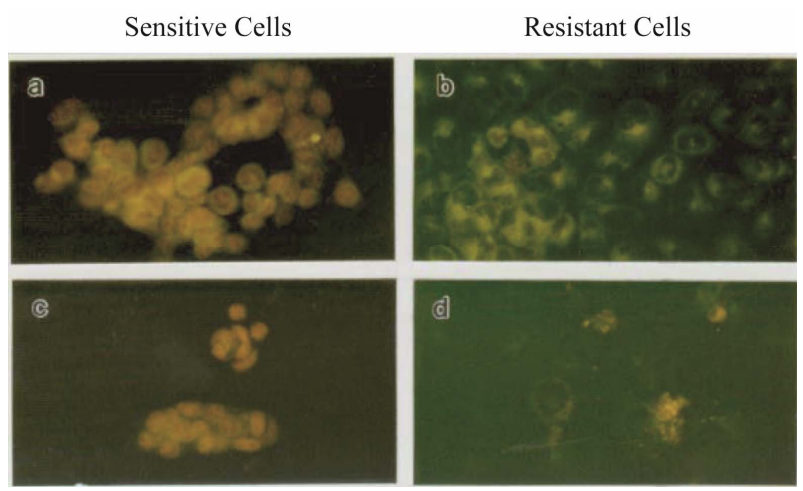

Figure 5. Fluorescent micrographs of Doxorubicin treated sensitive and resistant cell lines. The drug does not enter the nucleus of the resistant cells on the right.
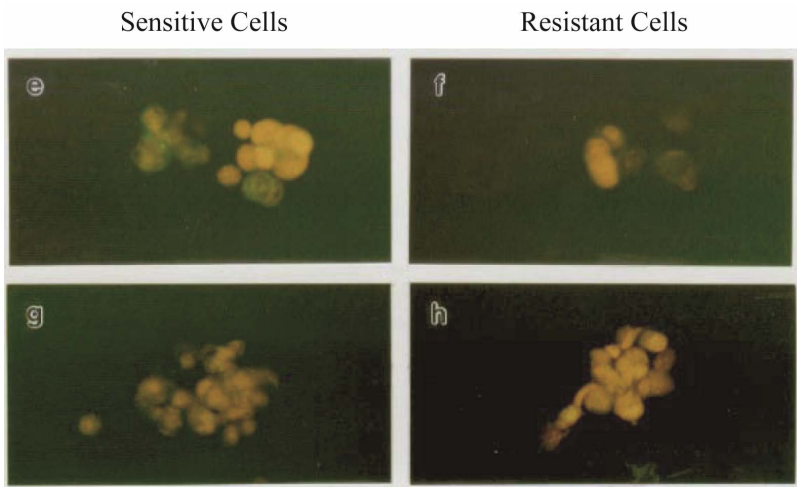

Figure 6. Fluorescent micrographs of the Dox-Ga-transferrin complex on sensitive and resistant cell lines. Demonstrates that the complex is evenly distributed in both cell lines and reverses drug resistance. 
metabolism by the combined targeting of multiple mechanisms of action. To better understand tumor iron metabolism we need to understand normal iron metabolism.

\subsection{Systemic and Cellular Iron Metabolism}

Systemic and cellular iron metabolism are tightly regulated and an important player in homeostasis is the hormone hepcidin. Hepcidin is a peptide hormone secreted from the liver [30]. Hepcidin has been shown to downregulate ferroprotein. It causes internalization and degradation of ferroprotein, and this is an important step in the homeostatic loop [30]. Excess iron in the diet stimulates hepcidin secretion which reduces Fe uptake into the bloodstream and promotes iron storage in ferritin [31]. $\mathrm{Yu}$, Kovacevic and Richardson [32] have presented a great review on iron regulation of the cell cycle. They discuss in detail many complex molecular events in cellular iron metabolism from uptake to storage. They also discuss the prospect of iron as a possible therapeutic strategy for cancer treatment. The effect and efficacy of different iron chelators on growth inhibition of cancer was evaluated. The main group of molecules involved in the regulation of the cell cycle and the molecular targets of iron chelators and their effects on the cell cycle was discussed.

Hentze, Muckenthaler, Galy, et al. [33] have published a great review on the regulation of mammalian iron metabolism. They state that iron metabolism is tightly balanced by two regulatory systems the systemic and the cellular. The systemic system relies on the iron hormone hepcidin and the iron exporter ferroportin. The cellular system is controlled through iron-regulatory proteins that bind iron-responsive elements in regulated messenger RNAs. They describe how the two systems "tango" together in a coordinated manner. Hepcidin plays a role in inflammation and stress, and the inflammatory cytokines IL-1 and IL-6 are potent stimulators of hepcidin expression. Endoplasmic reticulum (er) stress also increases hepcidin expression [34]. Weizer-Stern et al. [35] have suggested that iron deprivation and increased hepcidin expression could represent defense mechanisms against excessive cell proliferation and cancer. Ganz and Nemeth [36] have also shown that hepcidin secretion by the liver is stimulated by high iron levels and inflammatory cytokines like IL-6.

Much of the above evidence on hepcidin function has led us to believe that the hepcidin-ferroportin axis may be a target for cancer therapy. We also suspect that some type of dysregulation of hepcidin function or expression may contribute to dysfunction in iron metabolism and thus promote tumorigenesis. It is definite that iron plays a significant role in the proliferation, growth, and progression of cancer. Therefore, because mitochondrial iron metabolism may be the cradle of all iron metabolisms; we must address mitochondrial iron metabolism before embarking on the section of mitochondrial dysfunction in cancer.

\subsection{Mitochondrial Iron Metabolism}

Mitochondria are essential for iron metabolism, and a site for iron sulfur (FeS) cluster biosynthesis, and the only site for heme synthesis.

Richardson, Lane, and Becker et al. [37] have done a tremendous job reporting on the mitochondrial iron trafficking and the integration of iron metabolism between the mitochondrion and cytosol. It is somewhere in this integration of iron metabolism between the mitochondrion and the cytosol where we believe some dysfunction takes place that initiates mitochondrial dysfunction which contributes to the process of tumorigenesis. With so many molecular events and pathways involved this will be difficult to prove.

The mitochondrion is well known for its key role in energy production, electron transport, oxygen transport, and deoxynucleotide synthesis, but it is not well appreciated that it is a focal point of iron metabolism. There is very little known about the regulation of iron uptake by the mitochondrion, and how this is merged with iron metabolism in other organelles and the cytosol. The discovery of proteins involved in mitochondrial iron transport (mitoferrin 1 and 2) and storage (mitochondrial ferritin) has revealed that a communication exist between iron metabolism in the mitochondrion and the cytosol [37]. Intracellular iron transport and communication with the mitochondrion is complex, but once iron is transported out of the endosome by DMT1, it enters the labile and chelatable iron pool with complexes like iron citrate [38, 39].

This evidence is supported by studies with chelators that mobilize iron from cells $[40,41]$. Some believe that some of these compounds could remove iron from proteins and organelles because they chelate iron from low cytosolic M complexes [42]. An intimate direct transfer of iron from TF to the mitochondrion has been proposed to occur $[43,44]$. The direct transport of iron from the endosome into the mitochondrion has been described as the "kiss and run mechanism" $[44,45]$.

The exact molecular events involved in the contact between the endosome and the mitochondrion are unknown, but molecules involved in regulating the cytoskeleton, such as MRCKa [46], docking complexes myosin $\mathrm{Vb}$ [47], and also vesicular docking (e.g. Sec 11) play a role $[48,49]$. We believe that any minor dysregulation in the communication of iron between the mitochondrion and cytosol, mitochondrial iron import and mitochondrial iron metabolism definitely may lead to mitochondrial 
dysfunction and thus contribute to tumorigenesis. We will now embark on the journey of evaluating what is known about the possible role of mitochondrial dysfunction in tumorigenesis.

\section{Mitochondrial Dysfunction}

It is at this time we must briefly mention the work and contributions of Paul Ehrlich and Otto Warburg. Paul Ehrlich's magic bullet theory has inspired many generations of scientist to explore numerous molecular cancer therapeutics. He connected chemistry to biology and medicine; and predicted the existence of specific cell recaptors [50]. Otto Warburg in the 1930s, described a link between defects in mitochondrial physiology and tumorigenesis. He observed a significant increase in glycolysis and lactate production in the presence of oxygen without an increase and an occasional decrease in oxidative phosphorylation [51,52]. This phenomenon is known as aerobic glycolysis or the "Warburg effect" and is well documented in tumor cells. The work of the above two scientists has contributed much to the field of tumorigenesis, and those of us in the field should be extremely grateful for their contributions.

In 2005 Gottlieb and Tomlinson [53] did a tremendous job reporting on mitochondrial tumor suppressors with a genetic and biochemical update. They mention the work of Warburg, but it was 60 years after Warburg that the first genetic evidence that might explain the mechanisms of aerobic glycolysis was reported. There were many tumors shown to contain somatic mutations in mitochondrial DNA (MTDNA) [54,55]. It is thought that most are homoplastic and the outcome is non-functional oxidative phosphorylation, causing cells to increase glycolysis, the only other avenue for ATP (adenosine triphosphate) synthesis. However, there is limited evidence that indicates mitochondrial mutations might directly promote tumorigenesis $[56,57]$. There are some mitochondrial proteins encoded by nuclear genes that can be tumor suppressors, some are involved in benign and malignant tumors. Two of the proteins are the enzymes succinate dehydrogenase $(\mathrm{SDH})$ and fumarate hydratase also known as fumarase. Both of these enzymes are involved in the Kreb's cycle that connects glucose metabolism in the cytosol to mitochondrial oxidative phosphorylation. The inhibition of SDH has been linked to the induction of the hypoxicinducible factor (HIF). HIF is a transcription factor induced under low oxygen conditions [58]. SDH inhibition causes an accumulation of succinate, which transmits an oncogenic signal from the mitochondria to the cytosol, which inhibits HIF- $\alpha$ prolyl hydroxylase (PHD) activity leading to the stabilization of the HIF- $1 \alpha$ subunit at normal oxygen levels. The result is the transcription of genes involved in tumorigenesis, such as, the angiogene- sis factor vascular endothelial growth factor (VEGF). Therefore, succinate has been identified as a new intracellular messenger through discovery of the mitochondrion cytosol pathway (Figure 7).

Gottlieb and Tomlinson [53] have done a great job of discussing the link of mitochondrial dysfunction to cancer and we will now present some important aspects of their findings. The TCA cycle (tricarboxylic acid cycle also known as the Krebs cycle) is fundamental to the bioenergetics of cells, however, it is not exactly known how TCA dysfunction leads to cancer. To address that problem, they proposed several models. They included decreased programmed cell death (apoptosis), increased production of reactive oxygen species (ROS), and activetion of a hypoxia-like pathway under normoxic conditions (pseudohypoxia). Though impossible to distinguish between these options as they interact with each other, which leads to a complex grid of tumor regulatory systems. They still provided evidence to support the role for each of these three models in mitochondrial dysfunction induced tumorigenesis.

\subsection{Apoptosis}

Mitochondria play a central role in many apoptotic processes [59]. They have a crucial role in bioenergetics, but they are also a repository for several apoptogenic proteins, such as, cytochrome c, an appropriate signal causes release of these apoptogenic factors from the mitochondria to activate apoptosis. Interestingly mitochondria change their shape and bioenergetic performance during apoptosis $[59,60]$. The entire mitochondrial physiology is affected by many master regulators of apoptosis $[61,62]$.

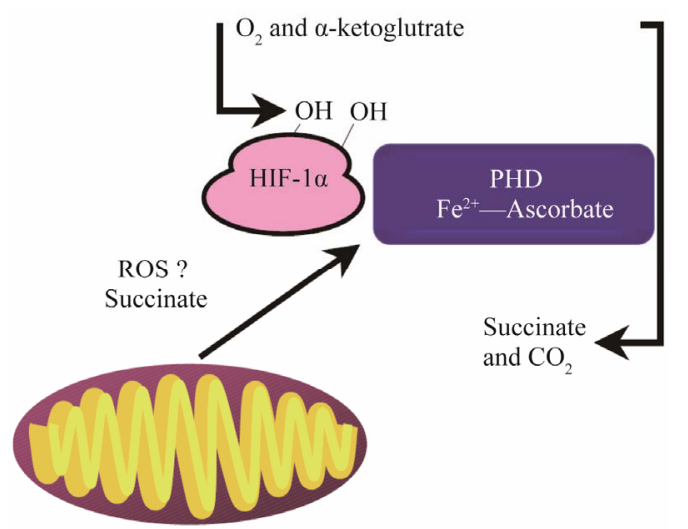

Figure 7. Mitochondrial dysfunction related to proyl hydroxylase (PHD) and hypoxia inducible factor activation. PHD hydroxylation requires oxygen and $\alpha$-ketoglutarate as substrates and ferrous iron $\left(\mathrm{Fe}^{2+}\right)$ and ascorbate as co-factors. If cells are deficient in succinate dehydrogenase, the increase succinate inhibits PHD leading to stabilization and activation of $\mathrm{HIF}-1 \alpha$ resulting in the transcription of genes involved in tumorigenesis. 
It is possible that the TCA cycle or ETC (electron transport chain) dysfunction could give rise to apoptotic resistant cells, thus giving rise to tumor development, and there have been several observations supporting this model $[63,64]$. Though complicated, an explanation of mitochondrial dysfunction causing a persistent apoptosis inhibiting effect may be upregulation of glycolysis and an alternate energy production metabolic pathway. Oxidative phosphorylation occurs at lower levels because of other mtDNA (mitochondrial DNA) mutations or inactivation of the TCA cycle. This becomes a problem for tumor cells as they have increased levels of protein and DNA synthesis. Glycolysis becomes the only other source of ATP in the tumor cells [65]. The glycolytic enzymes induced may regulate other cellular processes that include blocking of apoptosis [66,67]. Enabling cells to increase glucose metabolism might inactivate mitochondrial tumor suppressors and contribute to a persistent antiapoptotic effect.

\subsection{Redox Stress}

There is a paradox in the studies above $[63,64]$, that link inactivation of SDH to apoptosis, with a reduction in SDH activity there is associated increased production of ROS. Both studies showed that oxidative stress is the cause of acute apoptotic response in SDH deficient cells. Ishii et al. [64] have indicated that ROS has an additional role in the progression of tumors. They have shown that oxidative damage to nuclear DNA may lead to mutagenesis and observed the conversion of immortal fibroblast to transformed cells capable of generating tumors. However, this was more difficult in SDH-inhibited cells and these cells had to be incubated in culture for three months to become transformed. The long term culturing of wild type fibroblast were more malignant than tumors generated from the SDH inhibited cells (benign). This is inconsistent with the role of ROS and decreased apoptosis $[56,57]$. Storz [68] has stated that the role of ROS in inducing apoptosis is well documented; but it will be important to investigate the role of redox stress in promoting tumorigenesis in general, as well as, particularly in SDH deficient tumors.

\subsection{Pseudohypoxia}

This particular model implies a link between inactivation of SDH and initiation of the hypoxic response under normoxic conditions. This hypoxic response is mediated by the oxygen sensor HIF transcription factor. The HIF transcription factor is a heterodimeric complex comprised of HIF- $\alpha$ and HIF- $\beta$ subunits [69]. HIF- $\alpha$ protein levels are oxygen regulated, whereas HIF- $\beta$ is expressed constitutively. HIF physiological function is to promote the adaptation of cells to low oxygen conditions. This is done by inducing glycolysis as an anaerobic alternative to oxidative phosphorylation and by inducing angiogenesis to facilitate nutrient and oxygen supply into the hypoxic tissue [70]. This is also important for tumor growth and survival.

There is much evidence to connect SDH-deficient tumors to oxygen sensing in general and particularly to HIF. Cells commonly developing SDH deficient tumors are chromaffin cells of the adrenal gland (paraganglial cells, pheochromoctyoma and carotid body tumors respectively). These neural crest cells secrete catecholamine in response to low oxygen tension and are definitely part of the physiological oxygen sensing detection system during adulthood and in fetal development [71, 72]. There are numerous other type tumors that involve SDH-deficient or FH deficient tumors and others with genetic mutations in the VHL gene (von Hippel-Lindau) that are beyond the scope of this communication. However, it is important to note that germline mutations in these genes can lead to development of clear cell renal cell carcinoma and pheochromoctyoma [73,74].

We believe it is imperative that we address some of the advantages that pseudohypoxia gives to tumors and there are many that give these tumors an advantage for growth and survival, as well as, resistance to therapy.

First hypoxic regions in tumors select more aggressive cells that favor that environment [75]. The fact that these cells survive and grow in hypoxic conditions is dependent on HIF, which makes it an attractive target for cancer therapy [76]. HIF induced tumorigenesis stimulate mechanisms that induce genes that facilitate neovascularization, promote aerobic glycolysis and block apoptosis, aerobic glycolysis allows cells to increase energy production in the absence of oxidative phosphorylation. This allows these cells to survive and proliferate in a stressful environment [77]. The increased blood supply provides needed nutrients to the tumor. HIF involvement in apoptosis is less understood and may be cell type specific and dependent on the tumor microenvironment [78]. However, Shidara, Yamagata, and Kanamori et al. [57] have done a great job of reporting on the positive contributions of pathogenic mutations in the mitochondrial genome to the promotion of cancer by prevention from apoptosis. This was an extensive study involving the isolation and culture of cybrid cell lines and their cultures involved, detection of mutant mtDNA, measurement of oxygen consumption, transplantation of cybrids to form tumors in nude mice, histology, plasmid construction and transfection immunologic techniques, detection of apoptosis, and statistical analysis. This was a very detailed and interesting article worth the reader reviewing and because a physiologic advantage of two mutant mtDNAs in tu- 
morigenesis was revealed for the first time, it was felt that investigations of mtDNA will be very important in conquering cancers. Ma, Bai, Trieu, and Wong [79] have also reported on mitochondrial dysfunction in human breast cancer cells and their transmitochondrial cybrids.

Frezza, Pollard, and Gottlieb [80] have done a comprehensive study of inborn and acquired metabolic defects in cancer. They state that during the last decade, the identification of loss or gain of function mutations in key metabolic enzymes with a causal role in tumorigenesis has done much to awaken interest in Warburg's hypothesis. They discuss the molecular link between TCA cycle and HIF activation, and that accumulation of succinate in SDH deficient cells causes an inhibition of prolyL hydroxylases (PHDs) that are regulators of the stability of HIF-1 $\alpha$. During normal oxygen conditions PHDs hydroxylate two proline residues on the oxygen dependent domain for HIF- $1 \alpha$ degradation targeting it to proteasome ubiquitin degradation. This hydroxylation requires $\alpha$-ketoglutarate and oxygen and produces carbon dioxide and succinate. The excess succinate in SDH deficient cells inhibits activation of PHDs and leads to stabilization of HIF-1 $\alpha$ under normoxic conditions or so called pseudohypoxia. HIF-1 $\alpha$ with HIF-1 $\beta$ enters the nucleus and signal genes involved in tumorigenesis especially those involved in angiogenesis, etc. Biochemical studies revealed that PHD activity is competitively inhibited by succinate and fumarate, and that the ratio between succinate and $\alpha$-ketoglutarate rather than absolute concentrations of these metabolites dictates PHD activity. This information lead MacKenzie et al. [81] to use cell permeable esters of $\alpha$-ketoglutarate to reactivate the enzymatic activity of PHDs, thus inhibiting pseudohypoxia caused by the accumulation of succinate or fumarate [81, 82]. For a more complete discussion of all these complex mechanisms of inborn and acquired metabolic defects in cancer we recommend the excellent article by Frezza et $a l$. [80]. For those readers interested in a detailed discussion of mitochondrial and nuclear genes of the mitochondrial components in cancer, we suggest a great article by Kirches [83] published in Current Genomic in 2009.

Another great paper is entitled "Mitochondria in Cancer: At the Crossroads of Life and Death" published by Fogg, Lanning, and MacKeigan [84]. They do a very good job in discussing mitochondrial processes that play an important role in tumor initiation and progression. They have a unique way of explaining complex mechanisms in a simplified manner, a difficult task for most scientists. In their review they focus on three critical processes by which mitochondrial function may contribute to cancer. These three critical processes are: Alterations in glucose metabolism, production of reactive oxy- gen species (ROS), and the compromise of intrinsic apoptotic function. It is an excellent article that covers a broad range of mitochondrial dysfunction and its contribution to tumorigenesis. This read is very much recommended.

In the next section we will embark on the complex and very paradoxical third partner in this tumorigenic relationship, which is "Tumor Immunosuppression". We will attempt to present a reasonable discussion of a very diverse, complex, and confusing topic. It will be impossible to discuss every mechanism and pathway involved in tumor immunosuppression, but we will attempt to address as many of the most important immunosuppressive mechanisms as possible, especially those of the tumor microenvironment.

\section{Immunosuppression}

\subsection{Tumor Immunosuppression and Escape Mechanisms}

Cancer immunology is extremely complex and there are many molecular interactions between the tumor, tumor microenvironment, and the host. William Coley noted the fact that the immune system plays a role in inhibition of cancer progression in the late 1800s [85]. He contributed much to our knowledge of the role of the innate immune system and tumorigenesis, especially to our knowledge of sarcomas. His work created an interest in exploring the concept of cancer immunotherapy. Attempts to stimulate the immune system are not new, however, success has been limited and disappointing. Most of the early trials of cancer immunotherapy involved only some type of vaccine usually in patients with advanced bulky disease. There was no attention paid to host immunity and other tumor immunosuppressive mechanisms, therefore, results were poor and frustrating. We believe for cancer immunotherapy to be efficacious, it will take out of the box thinking and a combined approach. We must attempt to stimulate and inhibit arms of the immune system, and tumor escape mechanisms in the host and tumor microenvironment at the same time (Tables 1-4). We have so stated this in an article about combination cancer immunotherapy, recently published [86]. Another problem, in our opinion, is that the medical oncology community has been too involved with the tumor, stage of disease, and tumor biology and has ignored the host with the disease [87]. Before discussing some direct tumor and tumor microenvironment immunosuppressive mechanisms, we first should address the overlooked host immunity and escape mechanisms that are not directly related to the tumor. These mechanisms are initiated by stress of diagnosis, work-up, and treatment of the disease. This was recently emphasized in an article we published 
Table 1. Creating immunity.

What Do We Have to Do?

- Excite healthy innate immune system

- Stimulate and manipulate the adaptive immune system

- Disrup the tumor microenvironment escape mechanisms

Things Necessary for Successful Cancer Immunotherapy

- Healthy turned on innate immune system (pre-existing immunity)? Calreticulum

- Dying tumor cells (HMGB1) $\rightarrow$ Binding to TLR4-required for crosspresentation of tumor antigens

- Great effector system

- Ineffective suppressor system

- Disruption of the tumor microenvironment and escape, mechanisms

All of the above are intertwined and very related.

Table 2. Good effector system.

For Good Effector System

- Identify potent tumor associated antigens (TAAs)

- Ensure proper antigenic presentation and processing by APCs and dendritic cell-(HMBG1) $\rightarrow$ TLR4

- Which help promote maturation of APCs (IL-12) $\rightarrow$ what's responsible for tumor regression by Coley's Toxin

- Proper activation and stimulation of $\mathrm{CD}_{4}^{+}$helper cells and $\mathrm{CD}_{8}^{+}$ cytotoxic T-lymphocytes (must have good immune synapse), $\mathrm{MHC}$ I and II molecules

- Proper proportion of cytokines and co-stimulatory molecules

entitled: Cancer Immunotherapy More than Vaccines; "Psychoneuro-Immunooncology: Cancer, the Host, and the Surgeon" [88]. It is important to mention and discuss some of the very real immunosuppressive mechanisms before attacking the direct tumor and disease escape mechanisms. The latter are vast, complex and confusing, and many are paradoxical, and a few are organ specific. We believe if we are to improve the results of cancer immunotherapy, we must consider a combined multifaceted approach and these host and indirect escape mechanisms must be addressed.

The role of stress on the host immune system is too often overlooked, but it can be very detrimental especially when the immune system is probably already compromised. The diagnosis of cancer initiates a tremendous cascade of stressful events in the patient, all which impact cell mediated immunity (CMI). Therefore, tumor escape has already begun before the diagnosis; and is potentiated at diagnosis by stress associated with that diagnosis. The fact that tumor immunosuppression is already in place early in the disease is supported by the theory of immunoediting. Dunn et al. [89] have reported on cancer immunoediting from immunosurveillance to tumor escape, as have Kim et al. [90], both excellent
Table 3. Achieving a good effector system.

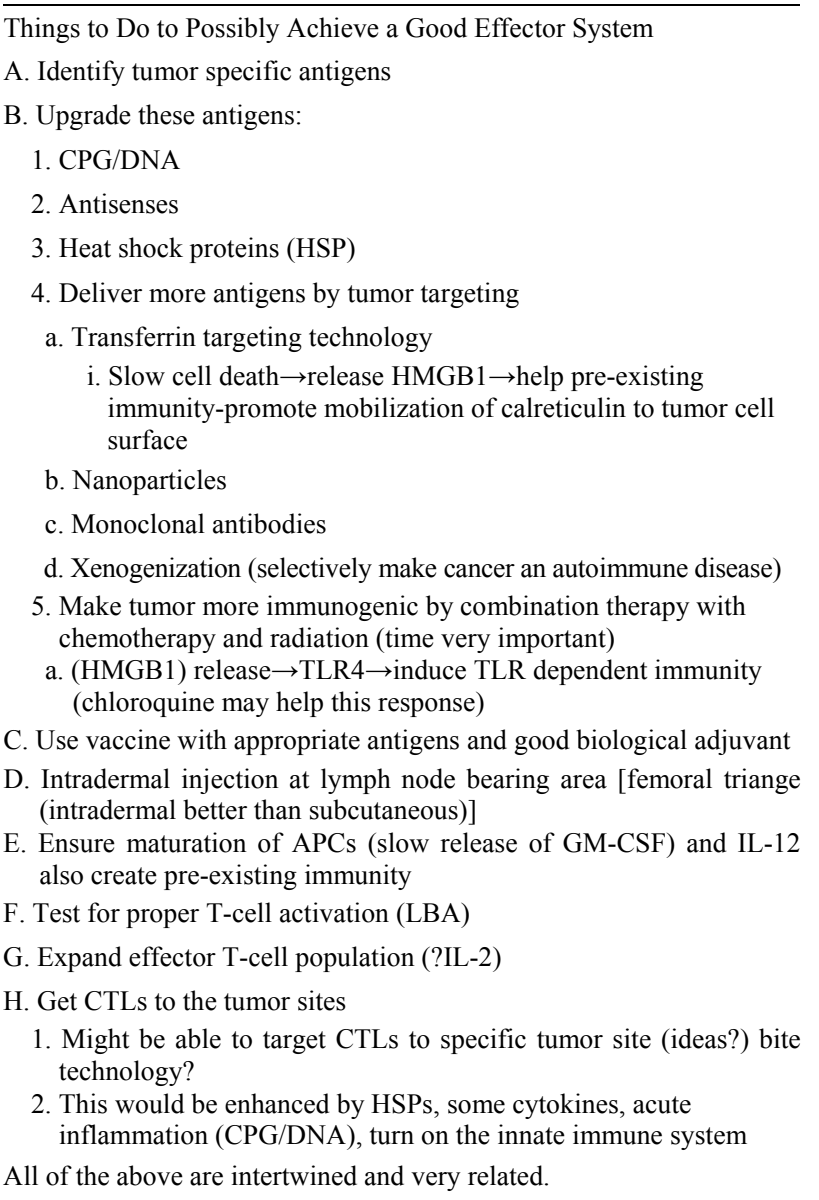

Table 4. Relation and integration of the suppressor side escape mechanisms.

The Suppressor Side, Tumor Microenvironment and Escape Mechanisms are Very Integrated and Related

A. Inhibit and delete regulatory T-cells (Foxp3)

B. Address dysfunctional T-cells (player are COX-2 $\rightarrow$ PGE-2, $\mathrm{cAMP} \rightarrow \mathrm{PKAI} \rightarrow \mathrm{LuK} \rightarrow$ Csk)

C. Create better environment by delivering IL-7 and IL-12

D. Attack the stroma

1. TAF

2. VEGF and tumor vascular endothelium directly (adhesion molecules)

3. Inhibit IDO, Arginase, IL-10, IL-6, TGF- $\beta$, and NOS

4. Supply proper nutrients, Arginine + Tryptophan

5. Decrease tumor Fe concentration because Fe inhibits NK cell function

6. Inhibit STAT3 in APCs at time of inducing acute inflammation

7. Inhibit antigen presentation attenuators

8. What about soluble T-cell receptors? If so, what role do they have? Are they present?

9. Myeloid derived suppressor cells

10. HIF-1 and glucose metabolism (resistance)

11. Address HLA-G expression 
articles. The concept of cancer immunoediting consist of three phases designated as: 1) elimination, 2) equilibrium, and 3) escape. During the elimination phase the immune system recognizes and destroys tumor cells. Later in the elimination phase there is only partial destruction of tumor cells, and a period of equilibrium develops between the tumor and the immune system. During this time the tumor remains dormant but continues to evolve and accumulate further changes, like DNA mutations and epigenetic modifications. This leads to the selection of tumor cells that are able to suppress and escape the immune systems antitumor response. This becomes the escape phase where the immune system can no longer inhibit tumor growth. Urosevic and Dummer [91] have done a great job in discussing the role of Human Leukocyte Antigen G (HLA-G) and cancer immunoediting. They discuss in detail the role of HLA-G in all three phases of cancer immunoediting, and also how HLA-G effects and interacts with the immunosuppressive molecules, cytokines, $\mathrm{NK}$ cells, $\mathrm{CD}_{4}^{+}, \mathrm{CD}_{8}^{+}, \mathrm{T}$-cells, and many other complex immunosuppressive mechanisms.

Tumor cells express HLA-G, but also do tumor infiltrating immune cells such as, lymphocytes, dendritic cells, and macrophages [92]. Unfortunately T-cells expressing HLA-G seem to exhibit marked immunosuppressive properties [93]. It is definite that HLA-G profoundly affects every aspect of human innate and active immunity [94,95]. We [96] have reported on the role of HLA-G in breast cancer immunosuppression and confirmed that it is a very important molecule involved in cancer immune evasion and progression. We postulated that HLA-G may be the main primary initiator (father) of cancer immune evasion, and once expressed causes a cascade of many immunosuppressive actions. Now that we have established that tumor immunosuppression is present early in local progression of the disease, we will now address escape mechanisms that are caused by psychic stress and the surgical, medical, and radiation treatment of the disease.

Psychic stress can have a devastating effect on host immunity. We believe during this early stressful period that a disastrous and potentially irreversible effect on the host immune system may occur, which might determine the final outcome and overall survival of the host. Therefore, it is important to address and attempt to reverse those immunosuppressive events at the time of diagnosis.

Most oncologists are unaware of the relationship between the brain and the immune system, however, the brain and the immune system are the two major adaptive body systems. The detail of this relationship has been presented in a great paper in 2000 by Elenkov, Wilder et al. [97]. They state that there is crosstalk between the brain and the immune system during an immune re- sponse. The sympathetic nerve is the integrative interface between the two supersystems. The major pathway systems involved in the crosstalk are the hypothalamic-pituitary-adrenal axis (HPA) and the sympathetic nervous system (SNS). Norepinephrine (NE) fulfills the role for neurotransmitter/modulator in lymphoid organs. When stimulated NE is released and targets immune cells expressing adrenoreceptors to respond. The NE and circulating catecholamines affect lymphocyte circulation, traffic, and proliferation.

There is evidence that NE and epinephrine through certain molecular pathways inhibit the production of Type I proinflammatory cytokines and stimulates the production of Type II anti-inflammatory cytokines. This causes a selective suppression of the Th1 response and CMI with a shift toward a Th2 response. A shift of Th1 to a Th2 response in the tumor microenvironment promotes cancer progression.

Ben-Eliyahu and his group from Israel [98] have contributed much to the field of Pschonueuroimmunology (PNI). They reported on the promotion of tumor metastasis by surgery and stress, thus laying the foundation for implications and the immunological basis for PNI. He emphasizes that stress and surgical excision of the primary tumor can promote tumor metastasis. He describes aspects of surgery that suppress CMI and neuroendocrine mechanisms causing suppression by surgery and stress. There is evidence that after tumor escape and local tumor growth CMI still contributes to systemic control of cancer by controlling macrometastatic disease and eliminateing residual disease after removal of the primary tumor. This is supported by some clinical studies on immune competence as a prognostic indicator of disease free survival $[99,100]$.

There are many cytokine responses to major surgery locally and systemically. There are proinflammatory cytokines and many Type II immunosuppressive cytokines that depress CMI [101]. Melamed, Rosenne, Sakhar et al. [102] have demonstrated suppression of NK cell activity by surgery in an animal model and that reversal of suppression could be done by the prophylactic use of a $\beta$ adrenergic antagonist and a prostaglandin synthesis inhibitor. Immune suppression was reversed by a $\beta$-blocker. Wu and Lanier [103] have shown that NK cells in animals are important in cancer control, while Andersen et al. [104] have shown that psychological and surgical stress suppress NK cell activity in animals and humans. However, some clinical studies have demonstrated that levels of NK cell activity at the time of surgery predicts long term survival $[105,106]$. Riesco [107] has reported that the pretreatment total lymphocyte count predicts overall survival of cancer patients, independent of other major prognostic factors. Fumgalli et al. [108] have 
shown that lymphocyte counts independently predicts overall survival in advanced cancer patients, and should be a biomarker for interleukin-2 (IL-2) immunotherapy.

\subsection{Iron Related Tumor Immunosuppression}

The role of iron in tumor immunosuppression is frequently overlooked and generally unknown, but it plays a significant role in tumor growth and tumor evasive mechanisms. In fact, iron could be one of the first players in tumor immunosuppression early in the immunoediting process. We have already earlier mentioned the role of iron in ribonucleotide reductase, DNA synthesis, and tumor growth. The accumulation of iron in the tumor during this early development just might be the culprit that tips the balance in the equilibrium phase and carries the tumor into the escape phase. We are presently exploring the relationship of tumor iron concentration and HLA-G expression (preliminary data not shown). We believe that tumor iron is important in the immunoediting process because we know the important role of NK cell activity in immune surveillance and eradication of early tumors; and we have shown that iron and ferritin inhibit NK cell cytolytic function.

Natural killer (NK) cells and nitric oxide (NO) are both important components of the innate immune response. NK cell cytolysis is mediated by the synthesis of NO. We have shown that iron inhibits the cytotoxicity of $\mathrm{NO}$ and the associated cytolysis of MCF-7 human breast cancer cells by NK cells [109]. In another study we investigated the antiproliferation effect of $\gamma \mathrm{TNF} \alpha$ and antisense oligonucleotides targeted to ferritin heavy chain (Fer-H) in MCF-7 cells. This study confirmed that iron protects tumor cells from NK cell mediated immune responses. The iron chelator deferoxamine increased NK cell cytolysis of MCF-7 breast cancer cells, however, the concentration was critical. A targeted antisense oligonucleotide downregulated Fer-H and synergistically increased the antitumor activity of $\gamma \mathrm{TNF} \alpha$ against the MCF-7 human breast cancer cell line. Fer-H inhibits $\mathrm{TNF} \alpha$ induced apoptosis by suppressing ROS. We have concluded that increased iron in tumor cells and their microenvironment protects the tumor from T-cell cytotoxicity by decreasing the sensitivity of tumor cells to NO. One mechanism of NO mediated cytotoxicity is by depletion of intracellular iron. This is to the best of our knowledge, the first time that increased iron has been shown to decrease NK cell cytolysis of tumor cells. We therefore, believe that manipulation of iron metabolism in tumor cells and their microenvironment could help reverse immune suppression (data not shown and to be published) [110].

Watts and Richardson [111] have done a tremendous job in discussing the mechanism of NO-mediated iron mobilization from cells. They state that many diverse biological effects of $\mathrm{NO}$ are through its binding ability to iron $(\mathrm{Fe})$. Cytotoxic actions of $\mathrm{NO}$ are found when it is produced in large quantities by cells such as, activated macrophages [112]. The NO produced by these systems inhibits the proliferation of intracellular pathogens and tumor cells [112-114]. These effects are because of the reactivity of $\mathrm{NO}$ with $\mathrm{Fe}$ in the $\mathrm{Fe}-\mathrm{S}$ centers of critical proteins. This includes aconitase and complex I and II of the electron transport chain [113-115]. The above findings now bring into play the role of mitochondrial dysfunction in tumor growth and tumor immunosuppression.

We have demonstrated the importance of iron in tumorigenesis, and the possibility of using iron chelators in cancer therapy, but copper is also very important. Cancer cells take up more copper $(\mathrm{Cu})$ than their normal counterparts. Copper is a metal that is important and essential for angiogenesis and metastasis [116]. Therefore, considering the critical roles of iron and copper, the development of novel $\mathrm{Fe}$ and $\mathrm{Cu}$ chelators are a potential anticancer strategy $[117,118]$. Lovejoy and Jansson et al. [119] have reported on the antitumor activity of a metalchelating compound Dp44mT. Its antitumor activity is mediated by formation of a redox-active copper complex that accumulates in lysosomes. They state that one of the most effective chelators is Dp44mT (di-2-pyridylhetone4,4,dimethyl-3-thiosemicarboazone). The mechanisms of action involves $\mathrm{Fe}$ chelation and redox cycling of its $\mathrm{Fe}$ complex to generate ROS [119] and its potent antitumor activity has been verified by others [120]. Rao and team have reported on a broad range of antitumor activity and also on topoisomerase II $\alpha$ inhibition $[121,122]$. Dp44mT binds $\mathrm{Cu}$ as well as $\mathrm{Fe}$ and both complexes are redox active, which contributes to their marked cytotoxicity [123]. There are other modes of anticancer activity of Dp44mT that includes inhibition of the metastasis suppressor protein, Ndrg-1, and modulation of many of the cell-cycle control proteins of the cyclin family (A, B, D1, D2, and D3) and also cyclin dependent kinases [117,118]. Their work has postulated a novel strategy for designing new therapeutics that activate the lysosomal apoptotic pathway by binding redox active $\mathrm{Cu}$.

Before entering the discussion of complex mechanisms involved in tumor immunosuppression in the tumor microenvironment, we need to briefly mention the connection of mitochondria to innate immunity. There have been two recent studies linking mitochondria to innate immunity by Seth et al. [124] and Xu et al. [125]. Both have identified a new intracellular signaling protein that is required for activating Type I interferon expression in response to viral infection. The Seth group [124] has shown the protein they call MAVS function requires that it be localized to the mitochondria. MAVS, therefore, 
provides the first link between mitochondria and the innate immune system. It is thought that MAVS signals through mitochondrial proteins, initiating a cascade of events leading to the induction of IFN- $\beta$. If mitochondria are important in innate immunity to eradicate viral infec- tions, they may also play a role in controlling or initiating cancer.

\subsection{Tumor Microenvironment Immunosuppression}

Tumor immunosuppressive mechanisms in the tumor microenvironment are numerous, complex, confusing, and sometimes paradoxical. It is impossible to address all mechanisms in one communication; and obviously there are many molecular events not known at this time. Therefore, we will attempt to present what we consider as some of the most important players in tumor microenvironment escape mechanisms. All of these complex mechanisms probably potentiate crosstalk between one another; thus augmenting immunosuppression within the microenvironment.

\subsubsection{STAT Proteins}

Some of the major players in cancer inflammation and progression are signal transducer and activator of transcription (STAT) proteins. These proteins determine whether immune responses promote or inhibit cancer in the tumor microenvironment. STAT3 and to some extent STAT5 when persistently activated increase tumor cell proliferation, invasion, and survival while inhibiting antitumor immunity. STAT3 persistent activation causes tumor promoting inflammation. The inflammation of cancer is marked by the presence of inflammatory mediators and specific inflammatory cells, including chemokines and cytokines [126]. STAT3 is crucial in producing and maintaining a proinflammatory tumorigenic microenvironment during cancer progression [127-129]. $\mathrm{Yu}$, Pardoll and Jove have published a tremendous review on STATs in cancer inflammation and immunity with the leading role by STAT3 (Figure 8) [130]. This review is a must read by those truly interested in the field of cancer immunosuppression. Another important core transcription factor in diverse immune responses is nuclear factor $k \mathrm{~B}(\mathrm{NF}-k \mathrm{~B})$. NF- $k \mathrm{~B}$ signals many major pathways for inflammation induced tumorigenesis and antitumor immunity [131,132]. Because they share central roles in cancer and inflammation STAT3 and NF- $k$ B are highly interconnected, and both serve as transcription factors regulating genes involved in cancer inflammatory mediators and tumor proliferation, angiogenesis, invasion and survival [133-135].

$$
\text { Importance of STAT3 Protein }
$$

Point of Convergence of Numberous Oncogene Signaling Pathwats-Constitutively Activated in Both Immune Cells and Tumor Cells in the Microenvironment

\author{
A. Inhibit danger signals and signaling in $\mathrm{CD}_{4}^{+}$ \\ T-regs required for expression of FOXP3, \\ IL- 10 , and TGF- $\beta$ \\ B. Propagates multiple levels of crosstalk between \\ tumor and immune cells - leading to suppression \\ C. STAT3 should be a molecular target (how could \\ we do?) \\ D. Necessary for evolution of Th17 cells and \\ expression of T-regs
}

Figure 8. Importance of STAT3 proteins.

NF- $k$ B has paradoxical roles in that it is crucial for cancer inflammatory conditions, but is also necessary for mediating antitumor immune response [132-134]. STAT3 activation inhibits antitumor immune responses by limiting STAT1 and NF- $k \mathrm{~B}$ expression of cytokines interferon- $\gamma($ IFN $\gamma)$ and IL-2 (Th1) cytokines which are important for innate and T-cell mediated antitumor immunity [136,137]. The STAT3 signaling in innate immune cells is required and promotes immunosuppressive tumor effects of myeloid-derived suppressor cells (MDSCs) and also tumor associated macrophages (TAMs) [138]. STAT3 is also necessary for the evolution of TH17 cells and expansion of T-regulatory cells, both which promote tumor growth [139-141].

\subsubsection{DLL-1 Notch Signaling}

Before we pursue other tumor escape mechanisms, we should mention briefly a recent article by Huang, Lin, and Shanker, et al. [142]. They state that little is known about the interplay between Notch and VEGF signaling pathways in the immune system especially regarding cancer-associated immunosuppression. They showed that tumor growth downregulates expression of DLL1 and DLL4 in the bone marrow hematopoietic environment and one causative factor is elevated VEGF. Selective stimulation of DLL1-Notch signaling dramatically slows tumor growth by rescuing tumor associated T-cell alterations. They postulate that potentiating of DLL-1 Notch signaling might be an attractive strategy to rescue tumor-associated T-cell immunosuppression.

\subsubsection{Transforming Growth Factor $\beta$ (TGF- $\beta$ )}

It is now well known that the tumor stroma and microenvironment play a role in tumor progression and metastasis. There is strong evidence that interactions between tumor cells and the stroma do promote cancer growth and metastasis [143]. One factor in the tumor microenvironment that is abundantly produced by stromal cells is 
transforming growth factor $\beta$ (TGF- $\beta$ ). TGF- $\beta$ is a multifunctional growth factor with complicated paradoxical roles in tumorigenesis [144]. It acts as a tumor suppressor during early stages of tumor development, but during later stages of tumorigenesis it functions as a growth factor to tumor cells causing them to be more motile, resistant to apoptosis, and more invasive. It is also involved in the epithelial to mesenchymal transition in tumor cells, thus increasing their metastatic potential. Welm [145] has written a great preview entitled "TGF- $\beta$ Primes Breast Tumor Cells for Metastasis" based on the work of Padua et al. [146]. They show that the cytokine TGF- $\beta$ in the breast tumor microenvironment primes cancer cells for lung metastasis. This property was due to the induction of angiopoietin-like 4 (ANGPTL4) by TGF- $\beta$ via the Smad signaling pathway. This pathway causes cancer cells entering the circulation to be retained in the lung. ANGPTL4 disrupts endothelial cell-cell junctions and facilitates transendothelial passage of tumor cells.

Ikushima and Miyazono have done a great job in a review on TGF- $\beta$ in the tumor microenvironment. Their article is entitled "TGF- $\beta$ Signaling: A Complex Web in Cancer Progression" [147]. This is definitely a great review for those interested in this topic. There is strong evidence that the TGF- $\beta$ signaling pathway serves as a tumor suppressor and for cancers to progress they must bypass this function. TFG- $\beta$ also has important roles in host-tumor mechanisms. In the tumor microenvironment TGF- $\beta$ affects the characteristics of tumor cells by many diverse mechanisms [148]. Ikushima and Miyazono [147] discuss some of the hundreds of factors that form a complex web that regulates TGF- $\beta$ signaling. The collapse of networks leads to a crash of the signaling pathway, and thus, results in tumorigenesis and progression of malignnant tumors.

Singha, Yeh, et al. [149] have studied the role of TMEPAI in breast cancer. TMEPAI is a TGF- $\beta$ induced transmembrane protein overexpressed in several cancers. They showed high expression of TMEPAI in triple negative breast cancer cell lines and primary breast cancers. Their results suggested that TMEPAI functions as a molecular switch in breast cancer that converts TGF- $\beta$ from tumor suppressor to a tumor promoter. There are many complex molecular mechanisms involved in this convesion of TGF- $\beta$ from tumor suppressor to tumor promoter.

\subsubsection{Cancer Associated Fibroblast (CAFs)}

Tumor associated fibroblast are known to promote tumor growth and progression. Casey, Eneman, Croker, et al. [150] have shown cancer associated fibroblast (CAFs) stimulated by TFG- $\beta$ increases the invasion rate of tumor cells. The CAFs in the reactive stroma are highly prolixferative and they express higher levels of extracellular matrix proteases and proteins. There is evidence that these proteases secreted by CAFs hydrolyze the basement membrane and these new proteins act as scaffolding for motile tumor cells to move, and also for the structural support of angiogenesis [151,152].

Kim, Stein, and O'Hare [153] have published a mini review on tumor and stromal interactions in breast cancer and the role of the stroma in tumorigenesis. They state as an oncogenic agent in tumorigenesis, the stroma can provoke tumorigenicity in adjacent cells in the absence of pre-existing tumor cells. Though most breast cancers originate from epithelial cells, the stroma in the tumor microenvironment is intimately involved in the growth and progression of cancer $[153,154]$. Oncogenic signals from CAFs can convert non-malignant epithelial cells to malignant ones; and the stroma is thought to promote tumorigenic activity in many ways, including production of matrix metalloproteases (MMPs) and, recruitment of macrophages, immune and inflammatory cells [155]. There is evidence that crosstalk between breast epithelial cells and the stroma (fibroblast and proteins) is critical for the invasion of tumor cells into the stroma and for development of metastasis. A major player in epitheliastromal interactions is TGF- $\beta$. It also regulates these interactions by adjusting the composition of the stroma. With the stroma emerging as a dominant factor in modulating tumorigenesis and many other tumor stroma interactions on cancer growth, the stroma could be a therapeutic target $[156,157]$. CAFs behave differently to mature fibroblast and also present a potential target for antitumor treatment [158].

Kalluri and Zeisberg [159] have done a tremendous review on fibroblast in cancer; and they go into much detail of all the complex and paradoxical functions of CAFs. They point out that tumors are like wounds that do not heal. CAFs are important in the production of growth factors, chemokines, and a extracellular matrix that facilitates angiogenic recruitment of pericytes and endothelial cells. Fibroblasts are involved in progression of cancer and are a target for cancer therapy. There is evidence that fibroblasts at the site of tumors are perpetually actvated.

Normal stroma in most organs contains a minimal number of fibroblast and a physiological ECM [160]; however, a reactive stroma contains many more oncogenic elements. This shows that reactive stroma stimulates oncogenic signals facilitating tumorigenesis [161, 162]. Epithelial to mesenchymal transition (EMT) causes cells to lose cell-to-cell contact and acquire mesenchymal properties and EMT cancer cells develop invasive and migratory properties $[163,164]$. It is possible that EMT could promote cancer progression by serving as a source of fibroblast-like cells with an altered genome. These 
findings indicate that EMT of cancer cells occurs, and probably accounts for a fraction of the CAFs present in tumors [163].

Though studies provide evidence that CAFs are tumor promoting other studies of normal fibroblast indicate they inhibit cancer progression. The loss of TGF- $\beta$ signaling in fibroblast results in prostate intraepithelial neoplasia (PIN) showing that normal fibroblasts suppress carcinogenic events [164], but how normal fibroblast prevent tumorigenesis is unclear [165]. One possible mechanism is that such fibroblast function in modulation of the host immune defense response. Fibroblast is a source of many immune cytokines, such as IFN $\gamma$, TNF- $\alpha$ and IL-6, which promote mobilization of cytotoxic lymphocytes, macrophages, and natural killer cells. It is believed that normal fibroblast help to prevent T-cell apoptosis [166].

Wallace, Leone, and Ostrowski [167] have done much to increase our knowledge of the role of tumor fibroblast and the tumor suppressor function of mammary stromal fibroblast. They accomplished this by developing a murine breast cancer model that ablates the PTEN tumor suppressor pathway in stromal fibroblast. They have shown the model useful in defining the mechanisms that underpin tumor-stroma crosstalk. We believe by conducting more experiments using this model, much more about oncogenic mechanisms of tumor escape in the tumor stromal microenvironment will be learned. This will allow us to develop therapies to target tumor stromal growth and immune suppressive mechanisms.

\subsubsection{Galectins}

When discussing factors involved in tumor immunosuppression in the tumor microenvironment, we must address the Galectins. Galectins are members of large carbohydrate binding lectins that share a highly conserved carbohydrate recognition domain (CRD) that is respons ble for $\beta$-galactosidase binding [168]. Many galectins have been thought to play a key role in cancer progresssion, especially Gal-1, -3 , and -9 [169]. Galectin- 1 is secreted in many tumor types and its expression correlates with tumor aggressiveness and metastasis [170,171]. Gal-1 expression in lung cancer is associated with larger tumors, node metastasis and overall lower survival [172].

Banh, Zhang, Cao, et al. have studied tumor Galectins1 versus host Galectin-1 and have determined that tumor Galectin-1 secretion is enhanced by hypoxia, and promotes tumor aggressiveness, angiogenesis, and T-cell apoptosis; and is more important than host Galectin-1. They showed that tumor Galectin-1 mediates tumor growth and metastasis through regulation of T-cell apoptosis [173]. Rubenstein and colleagues have shown in experiments that the level of Gal-1 secretion in cul- tured supernatant correlated with the extent of tumorinduced T-cell death in both murine and human melanoma cells. The targeted inhibition of Gal-1 expression in vivo rendered mice resistant to tumor challenge, which requires a functional $\mathrm{CD}_{4}^{+}$and $\mathrm{CD}_{8}^{+}$T-cell response. This suggests that Gal-1 contributes to tumor immune privilege by modulating subset T-cell survival [174]. Thijssen, Barkan, Shoji, et al. [175] have shown that tumor cells secrete Gal-1 to enhance endothelial cell activity. Their data definitely identified Gal-1 as a proangiogenic factor. Gal-1 has been associated with tumor escape mechanisms [176]; however, the Thijssen group [175] could not confirm that Gal-1 was immunosuppressive in the tumor microenvironment. Therefore, Gal-1 promotes tumor immunosuppression by inhibiting effecttor $\mathrm{CD}_{8}^{+} \mathrm{T}$-cell function.

\subsubsection{Lymphoid Tissue Like Structures}

Human tumors suppress and escape the immune system to enhance their survival. Many tumor cells escape immune detection by downregulating the expression of antigenic proteins on their cell surface, thus making them invisible to cytotoxic T-lymphocytes [177]. However, most tumors secrete proteins and cytokines that inhibit effector T-cell responses and induce the production of T-regulatory cells that suppress immune function [178]. Zindl and Chaplin [179] have done a great job on the perspective of a paper by Shields, Kourtis, Tomei, et al. [180] which shows how malignant cells induced the formation of lymphoid tissue-like structures that assist the tumor in evading host immunity. Shields et al. [180] revealed that mouse and human melanoma express the chemokines CCL21 that recruits lymphoid tissue inducer cells (LTi). This causes a reorganization of the tumor's stroma and the recruitment of $\mathrm{CD}_{4}^{+}$T-regulatory cells, myeloid derived suppressor cells, and other immune cells. They studied the mechanisms of tumor escape that bears similarities to the tolerance maintaining function of lymph node stroma. These lymphoid-like structures in the stroma promote immune tolerance, similar to the tolerance functions of the lymph node stroma. Specialized stromal cells in the node paracortex called fibroblastic reticular cells secrete the CCRL ligands CCL19 and CCL21 which promote interactions between $\mathrm{CCR} 7^{+}$ T-cells and antigen presenting cells (APCs) needed for T-cell antigen presentation and priming. They [181] recently showed that invasive tumor cells secrete CCL21 and verified it in the present study [180] in a three dimensional culture of several human tumor cell lines. The expression of CCL19 and CCL21 in non-lymphoid and tumor tissue is related to inflammation and immunosuppression. They support a stroma and microenvironment for T-reg cells and shift macrophages from M1 to the M2 
phenotype. CCL21 also attracts myeloid derived suppressor cells (MDSCs) thus the tumor microenvironment becomes a Th2 immunosuppressive environment. Tumors expressing CCL21 also express the catabolic enzyme indoleamine 2,3-dioxygenase (IDO) [182], a potent tumor immune suppressor and also complement recaptor-1 related gene/protein Crrg a complement regulating protein that can inhibit antitumor immunity [183]. Thus tumors with a lymphoid like stroma secreting the chemokines CCL19 and CCL21 are extremely evasive of the host immune system (Figure 9).

\subsubsection{Myeloid Derived Suppressor Cells (MDSCs)}

During this communication we have touched on the role of myeloid derived suppressor cells (MDSCs) in tumor immunosuppression, and now we would like to expand our knowledge on tumor escape mechanisms governed by MDSCs. They seem to play a critical factor in T-cell nonresponsiveness.

One of the major mechanisms of tumor escape is defective T-cell function, and that is one of the critical factors that limits the success of cancer vaccines. Nagaraj and Gabrilovich [184] have presented a great review on tumor escape mechanisms governed by MDSCs. MDSCs are defined as $\mathrm{CD} 14^{-} \mathrm{CD} 11 \mathrm{~b}^{+}$cells or cells that express the myeloid marker CD33. MDSCs exert their immunosuppressive effects in many different ways depending on their location and specific characteristics of the tumor. Some of the factors involved in MDSC immune suppression are arginase, reactive oxygen and nitrogen species, and including surface molecules. At the tumor site it is mainly antigen nonspecific and is mediated by production of nitric oxide (NO) in combination with high arginase activity. The high arginase activity, in combination with increase NO production by MDSCs, results in marked T-cell apoptosis and increased production of reactive oxygen species, inducing peroxynitrites and hydrogen peroxide $\left(\mathrm{H}_{2} \mathrm{O}_{2}\right)$ by MDSCs [185]. They [186] have shown that a peroxynitrites scavenger eliminated MDSC induced T-cell tolerance which suggested that ROS could be responsible for MDSC mediated $\mathrm{CD}_{8}^{+}$ T-cell tolerance. Bronte, Kasic, Gri, et al. [187] have stated that restoration of $\mathrm{T}$-cell responsiveness to the tumor could be achieved by inhibiting simultaneously inducible NO synthase and arginase activity. It is thought that the blockade of peroxynitrites generation and use of scavengers could be an opportunity to decrease tumor associated T-cell tolerance and augment efficacy of cancer immunotherapy.

\subsubsection{Tumor Associated Macrophages (TAMs)}

Another important cell involved in antitumor immunity is the macrophage. Quin and Pollard [188] have published a

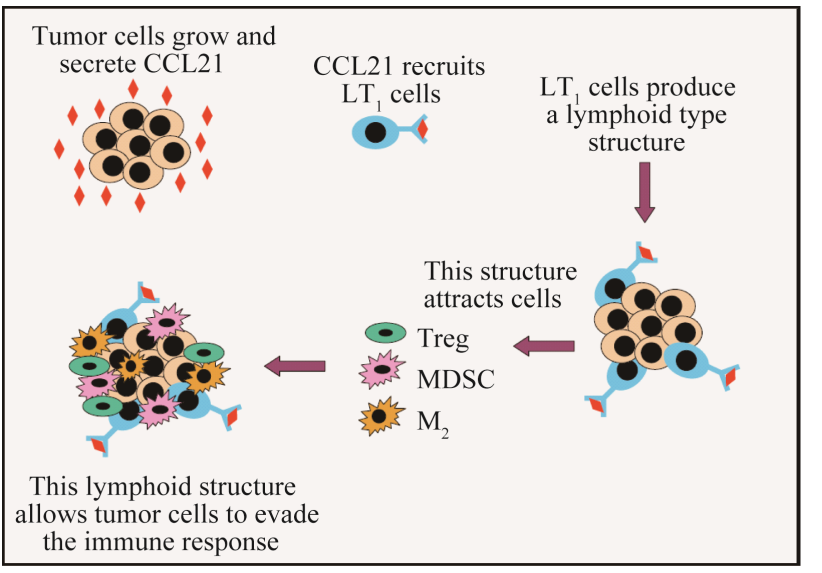

Figure 9. Lymphoid structure formation: tumor cells secrete CCL21 which recruits $\mathrm{LT}_{1}$ cells. $\mathrm{LT}_{1}$ cell generate a lymphoid structure which attracts Tregs, MDSCs, and $\mathbf{M}_{2}$ macrophages. The result is tumor cell immune evasion.

tremendous review on how macrophage diversity enhances tumor progression and metastasis. They state that there is strong clinical and experimental evidence that macrophages promote cancer initiation and malignant progression. Macrophages create an inflammatory environment early promoting growth and later macrophages stimulate angiogenesis, tumor cell invasion and migration, and later also suppress antitumor immunity. They prepare target tissue for arrival of tumor cells to establish metastasis.

The macrophage lineage is important in determining the type of immune response in the tumor microenvironment and Pollard [189] has attempted to define important macrophage subsets. His most successful classification was applied to subsets participating in specific immunological responses. There were the activated macrophage that was involved in a Type I helper response or the Th1 cells. This cell population is activated by interferon gamma and engagement of Toll-like recap- tors (TLRs). It is characterized by increased expression of major histocompatibility complex (MHC) Class II production of tumor necrosis alpha (TNF $\alpha)$ and inter-leukin-12 (IL-12), with generation of nitric oxide (NO) and reactive oxygen species (ROS). This type has the ability to kill pathogens and cancer cells. The contrast is the alternatively activated macrophage that differentiates its response to IL-4 and IL-13. These are involved in Th2type responses, and also wound healing and humoral immunity [190]. Mantovani and team [191] have postulated that tumor macrophages are nearly devoid of activated M1 macrophages and are biased to the M2 type macrophage, thus promoting tumor escape and decreasing antitumor immunity.

Macrophages play a central role in immunoregulation within the tumor. The result in some cases can be tumor 
rejection, as both dendritic cells and macrophages are able to present antigens to cytotoxic T-cells, and macro- phages are extremely competent at tumor killing. The pioneering work of Fidler and colleagues [192] showed that macrophages could kill tumor cells and eradicate metastasis.

Guiducci et al. [193] have shown that tumor inhibition can be accomplished by treating tumors with CPG together with anti IL-10. This treatment activates Toll-like receptors and blocks immunosuppression respectively, but in the majority of tumors there is not enough inhibittion of growth due to many other tumor immunosuppressive mechanisms. These TAMs represent an immunological regulatory type characterized by downregulation transcripts involved in activation like IL-12, IL-18, and TLR signaling, with upregulation of transcripts of alternatively macrophages such as arginase producing [194]. There are several mechanisms that macrophages use to inhibit T-cell responses. One is that they produce IL-10 that induces monocytes to express the costimulatory molecule programmed cell death ligand (PD-L1), which suppresses cytotoxic T-cell responses [195]. The important point about TAMs is that they are markedly different from MDSCs [196], but it is still unresolved whether they can differentiate solely into mature granulocytes or become macrophages in vivo; or are there other more myeloid cell subpopulations?

We have previously mentioned some vital roles of hypoxia-inducible factor- $1 \alpha$ in tumor immunosuppression, but Doedens, Stockman, Rubinstien, and colleagues [197] have shown that macrophage expression of hypoxia-inducible factor- $1 \alpha$ suppresses T-cell function and promotes tumor progression. They showed that targeted deletion of the transcription factor HIF- $1 \alpha$ in tumor macrophages of a murine model resulted in reduced tumor growth without altering levels of vascular endothelial growth factor and vascularization. Hypoxia augmented the macrophage T-cell suppression in vitro depending on the expression of macrophage HIF-1 $\alpha$. Hypoxia is a hallmark of neoplastic growth, and low oxygen tension stimulate myeloid cells to increase levels of iNOS and arginase suggesting a role for HIF- $1 \alpha$-dependent hypoxic regulation of iNOS and arginase in myeloid cell modulated T-cell suppression [198]. They [197] showed that loss of HIF-1 $\alpha$ in TAM relieves hypoxia induced expression of T-cell activation, and that loss of HIF- $1 \alpha$ in myeloid cells inhibits tumor progression. Their data confirms that there is a hypoxia-induced and HIF- $1 \alpha$ dependent suppression of the adaptive immune system by the innate immune system in solid tumors. Over the last several paragraphs we have shown how TAMs play a very diverse and significant role for tumor escape mechanisms in the tumor microenvironment (Figure 10).

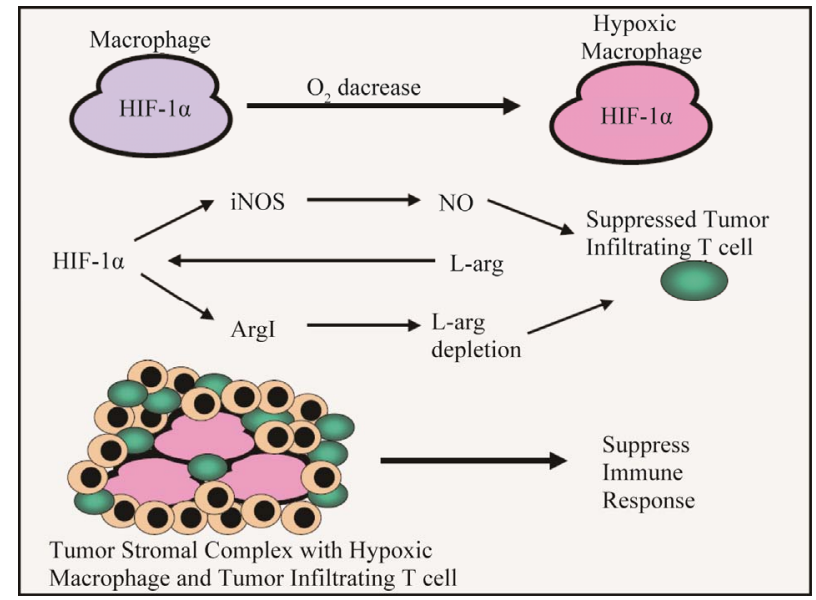

Figure 10. Diagram of HIF-1 $\alpha$ activation of T-cell suppression in hypoxic areas of tumors.

There are probably many more, and we are convinced that there is crosstalk, potentiation and synergism between all tumor escape mechanisms, even if they are not in the same sequence. With that being stated, we will attempt to present some major tumor immunosuppressive roles played by FoxP3 T-regulatory cells.

\subsubsection{Regulatory T-Cells}

Sakaguchi, Yamaguchi, and team [199] have done a great review on regulatory T-cells and immune tolerance. Regulatory T-cells (Tregs) are indispensable in maintaining immunological unresponsiveness to self-antigens and preventing excessive immune responses harmful to the host. They go into extreme detail discussing the origin, development, and different mechanisms of function of Tregs in immunological homeostasis. They discuss the exact roles of Tregs in immune homeostasis and selftolerance, the molecular and cell basis of their development and function. They suggest that Tregs could be exploited at the cellular and molecular levels to control physiological and pathological immune responses. Those interested in Tregs should definitely read this review.

FoxP3 (forkhead box P3) is a member of the fork/ head/winged-helix family of transcription factors; and is a master regulator of Treg development and function. This transcription factor is critical for $\alpha / \beta$ TCR-positive T-cells to differentiate to Tregs in the thymus and a high level expression confers suppressive activity to normal non-Treg cells. Another molecule critical for the function of Tregs is interleukin 2 (IL-2). The Treg marker CD25 is a component of the high affinity IL-2 receptor (IL-2R) and is essential in Treg development.

IL-2 has multiple targets, such as $\mathrm{CD}_{4}^{+}$and $\mathrm{CD}_{8}^{+} \mathrm{T}$ and $\mathrm{B}$ cells and also natural killer cells. It has many pleiotropic functions and very contradictory immune effector responses. It promotes differentiation of $\mathrm{CD}_{4}^{+} \mathrm{T}$-cells to 
Th1 and Th2 cells and expands natural killer cells and $\mathrm{CD}_{8}^{+}$and memory T-cells. On the contrary IL-2 promotes apoptosis of antigen-activated T-cells. It also expands and maintains $\mathrm{FoxP}^{+}$natural (Tregs), and facilitates TGF- $\beta$ dependent differentiation of naïve T-cells to FoxP $^{+}$(Tregs). Interestingly IL-2 inhibits TGF- $\beta /$ IL-6 dependent differentiation of naïve T-cells to inflammatory Th17 cells, thus it plays a role in negative feedback control of immune responses [200].

It is a very delicate balance to evolve a regulatory mechanism to allow the immune system to protect against invading pathogens while avoiding destruction of the host tissue bearing receptors specific for self-antigens. Rudensky, Gavin, and Zheng [201] have presented a minireview discussing how FoxP3 and NFAT are partners in tolerance. They discuss the paper by Wu et al. [202] that is very complete and complex explaining how FoxP3 controls regulatory T-cell function through cooperation with NFAT. They discuss in detail how antigen stimulation of immune cells activates NFAT, a key regulator of T-cell activation and anergy, and that regulatory T-cell (Treg) function is mediated by a cooperative complex of NFAT with FoxP3. Thus when NFAT switches transcriptional partners from AP-1 to FoxP3 it converts acute T-cell activation into the suppressor program of Tregs. This of course is a very complicated molecular process beyond the scope of this communication.

The exact mechanism of the suppression of effector T-cells by Tregs is not definitely known, but Tasken and his colleagues have done some excellent work in this area [203]. They state that in addition to naturally occurring Tregs there are also adaptive Tregs which represent a less characterized suppressive subpopulation of $\mathrm{CD}_{4}^{+}$ $\mathrm{T}$-cells that are induced by continuous antigenic exposure. Thornton and Shevach [204] have stated that Tregs suppress responding T-cells in an antigen-nonspecific manner, and they need through the TCR to achieve suppressive activity. Therefore, it is likely that adaptive Tregs are generated from the peripheral $\mathrm{T}$-cell repertoire and can be induced by IL-10 and TGF- $\beta[205,206]$.

Mahic, Yaqub, Johansson, et al. [203] of the Tasken group have revealed that $\mathrm{FoxP} 3+\mathrm{CD} 4+\mathrm{CD} 25+$ adaptive regulatory T-cells express cyclooxygenase 2 (COX-2) and suppress effector T-cells by a prostaglandin E 2 (PGE2 ) dependent mechanism. They have shown that adaptive Tregs induced in vitro that express COX-2 and FoxP3 produce PGE-2 and that they suppress effector T-cell responses that are reversed by COX inhibitors and PGE2 receptor antagonist. It was also shown that resting CD4+ CD25-T-cells treated with PGE-2 induced FoxP3 expression. Prostaglandins exert a very strong immunomodulatory activity within the immune system. PGE-2 binds to the $\mathrm{G}$ protein coupled receptors EP2 and EP4 and inhibit
T-cell immune responses by eliciting a cAMP (Protein kinase A) CSK inhibitory pathway localized to lipid rafts [207-209].

$\mathrm{Lu}$ [210] has published an editorial on FoxP3 expression and prognosis, and the role of both the tumor and $\mathrm{T}$-cells. FoxP ${ }^{+}$Tregs in patients with ovarian and breast cancer have been reported, and the abundance of $\mathrm{FoxP}^{+}$ Tregs in tumors has been correlated with a poor prognosis $[211,212]$. It has been recently shown that a complete pathologic response of breast cancer after neoadjuvant chemotherapy is associated with disappearance of tumor infiltrating FoxP3 ${ }^{+}$T-regulatory cells [213]. It has been shown only recently that the tumor cell can also express FoxP3, and interestingly vaccination to eradicate $\mathrm{FoxP}^{+}$ expressing cells enhances tumor immunity [214]. Merlo and his colleagues [215] have suggested that the expression level of FoxP3 in breast cancer cells is associated with patient survival. Immunohistochemical staining studies showed that $\mathrm{FoxP}^{+}$expression in tumors was associated with poor survival and the risk was increased with the intensity of $\mathrm{FoxP}^{+}$immunostaining. They point out that the precise mechanisms by which Tregs suppress tumor immunity is not clear. There are reports of direct inhibition by cell-cell contact and the indirect inhibition through secretion of anti-inflammatory cytokines, such as, IL-10 and TGF- $\beta$ [216,217]. Merlo et al. [215] state that FoxP $^{+}$expression should be an independent new prognostic marker for breast cancer with a predictive power like that of lymph node status.

Liu, Lang, Zhao, et al. [218] have done a great job studying $\mathrm{CD}_{8}^{+}$cytotoxic T-cell and FoxP3 ${ }^{+} \mathrm{T}$-cell infiltration in relation to breast cancer survival and molecular subtypes. Tregs and cytotoxic T lymphocytes (CTLs) in breast cancer were addressed by immunohistochemistry in 1270 cases of invasive breast cancer. They looked at the infiltration of both in the tumor with the associations of histopathological features, molecular subtypes and patient survival. The infiltrate of both type cells were observed within the tumor bed and surrounding tumor tissue. The increased infiltration of CTLs and Tregs were significantly common in tumors with unfavorable histologic features, with a high histologic grade and negative ER, PR status. A high density of Treg infiltration was also associated with a high Her 2 tumor overexpression with a decreased overall survival (OS) and progresssion free survival (PFS). However, a high CTL/Treg ratio in the tissue surrounding the tumor was associated significantly with improved OS and PFS. It was shown that the prognostic significance of CTLs and Tregs in breast carcinoma depends on their relative density and location within the tumor. The density of Treg infiltrates within the tumor and the peritumoral CTL/Treg ratio are independent prognostic factors. They are also correlated with 
the prognosis of the molecular subtypes of breast carcinoma. They postulate that the CTL/Treg ratio in the tumor and peritumoral microenvironment could serve as a potential target for immunotherapy to combat against the aggressive subtypes of breast carcinoma.

For tumor immunotherapy to be effective a major goal is the generation of $\mathrm{CD}_{8}^{+} \mathrm{T}$-cell memory, as well as, activation of $\mathrm{CD}_{8}^{+}$effector cells. Surgery is still the leading therapy for solid tumors, but memory T-cell responses are probably required for the prevention of tumor recurrence and metastasis, a major problem is that most human tumors are poorly immunogenic and most tumor antigens are unchanged self-proteins. There is some evidence that Tregs may prevent memory against poorly immunogenic tumors.

Cote' and colleagues have shown in a mouse tumor model that removal of Tregs cells during tumor growth drives the natural development of T-cell memory [219]. They [220] have recently reported a review of their work and others on tumor specific T-cell memory and problems on clearing the regulatory T-cell hurdle. It is suggested by them that Treg depletion several days prior to surgery could potentially be done to prevent recurrence of retained minimal disease. Their work showed that poorly immunogenic tumors can induce tumor specific T-cell memory when Treg suppression is overcome and that implementing immunotherapy in conjunction with surgery and Treg depletion may provide the cancer patient a chance for a long-lived survival without recurrent or metastatic disease [220].

Tanaka and his team [221] have demonstrated in a tumor model that depletion of $\mathrm{CD} 4+\mathrm{CD} 25+$ regulatory cells augments the generation of specific immune cells in tumor draining lymph nodes. Though depletion of Tregs was insufficient to eradicate tumors, it did augment the sensitization of immune T-cells in the draining lymph nodes, and thus does improve adoptive immunotherapy.

\subsubsection{Cytotoxic T-Lymphocyte Antigen-4 (CTLA-4)}

Another novel strategy for combating tumor immunosuppression is to target cytotoxic T-lymphocyte antigen4 (CTLA-4). The advantage of interrupting T-cell downregulatory pathways is that targeting the host's immune system eliminated the necessity to identify specific tumor antigens, thus concentrating on a specific immune response. CTLA-4 is that attractive target, and O'Day, Hamid, and Urba [222] have done a great job in explaining the mechanisms of action of CTLA-4. They point out that CTLA-4 is a very important immunity checkpoint. Once T-cell activation takes place an important step limiting the proliferative response of the activated T-cells takes place to prevent tissue injury, thus maintaining peripheral tolerance. CTLA-4, is therefore an important checkpoint that controls the intensity and duration of the immune response and that checkpoint is at the site of the APC interaction at the immunological synapse. CTLA-4 binds both CD80 and CD86 with 100-fold greater affinity than the $\mathrm{CD} 28$ receptor and this competitive ligand binding turns off the activated T-cell. This decreases the T-cell population to a small pool of memory T-cells [223].

It is obvious from much of the above discussion that the mechanisms involved in tumor evasion and immunosuppression are numerous, very complex, poorly understood, and many are probably still unknown. With that being the case, we will try to present a few more methods of cancer immune suppression that have been recently reported. It is impossible to discuss in detail the extensive mechanisms of action of these tumor evasive strategies but we will touch on the highlights of some of the more interesting mechanisms of tumor immunosuppression.

\subsubsection{Cytokines}

There are many immunosuppressive cytokines that subvert innate and adaptive immune responses during the progression of cancer. Interleukin-18 (IL-18) is an inflammatory cytokine that accumulates in cancer patients; however, its pathophysiological role is unclear. Terme, Ullrich, Aymeric, Meinhardt, et al. have presented a priority report demonstrating that IL-18 induces PD-1 dependent immunosuppression in cancer [224]. In their study they showed that low levels of either exogenous or tumor derived IL-18 suppresses the NK cell arm of tumor immunosurveillance. Tumor cell produced IL-18 promotes development of NK-controlled metastasis in a PD-1 dependent manner. It is known that tumor cells secrete immunosuppressive soluble factors, such as, IL-6, TGF- $\beta$, VEGF, macrophage colony stimulating factor and indoleamine 2,3-dioxygenase. These factors directly block T-cell proliferation, promote T-cell apoptosis, and make tumor cells resistant to T-cell attack [225]. IL-23 is also released in the tumor microenvironment, and it is a key NK cell immunosuppressant [226]. Terme and colleagues [224] report that PD-1 is expressed by activated mature NK cells in the lymphoid organs of tumor bearers, and it is upregulated by IL-18. The elimination or inhibittion of IL-18 stimulates NK cell dependent immunosurveillance in various tumor models. These results confirm that IL-18 is an immunosuppressive cytokine in cancer.

Tumor cells evade the immune system in many ways, but Mamessier, Sylvain, Bertucci, Castellano et al. have shown that breast tumor cells induce self-tolerance mechanisms to avoid NKG2D-mediated and DNAM-mediated NK cell recognition [227]. They found that NKG2D ligands and DNAM ligands are expressed in all breast 
tumor subtypes. It was shown that NK cell mediated cytotoxicity is mainly HLA and NKG-2D and DNAM dependent. Their study showed that breast cancer cells regardless of subtype develop different mechanisms to escape NK cell antitumor immunity.

\subsubsection{Cellular Adhesion Molecules (CAMs)}

Cellular adhesion molecules (CAMs) play an important role in tumorigenesis, and also in host immunity and defense mechanisms. There are three very important CAMs: vascular cell adhesion molecule (VCAM), intercellular adhesion molecule (ICAM), and E-selectin; and a downregulation of all of these CAMs were noted in node positive breast cancer in comparison to node negative cases of breast cancer [228]. VCAM is a glycoprotein expressed on the surface of stimulated endothelial cells [229] and it is an adhesion molecule for many cell types including lymphocytes [230]. Increased VCAM serum concentrations have been noted in most cancers. They [228] found that in node positive breast cancer there was significant downregulation of adhesion molecules, and their data suggested that VCAM was an independent predictive factor of nodal metastasis. This was the first time to be reported that downregulation of adhesion molecules occurs in node positive breast cancer. They believe that shedding of adhesion molecules by activated endothelial and tumor cells might allow tumor cells to escape surveillance from cytotoxic T-cells and natural killer cells, thus permitting invasion and progression of disease.

We have been working on the role of adhesion molecules in the breast cancer tumor microenvironment as an escape mechanism since 2005 . We found by IHC especially in high grade tumors, that there were reduced levels of VCAM-1 and ICAM-1 expressed on the tumor vessel endothelium (data not shown). There is also some suggestion that there is dysfunction of lymphocyte function-associated antigen 1 (LFA-1) on the effector lymphocytes in the Stage IV breast cancer patient. We have felt for some time that a major tumor escape mechanism is dysfunction of endothelial adhesion molecules, which prevents cytotoxic effector $\mathrm{CD}_{8}^{+}$T-cells and NK cells from entering into the tumor microenvironment. We have had many patients on our immunotherapy protocol that had great T-cell immunity confirmed by a lymphblastogenesis assay (LBA); but yet had progressive disease due to tumor escape mechanisms.

Our suspicions about endothelial adhesion molecules and tumor evasion has recently been confirmed by Delfortne, Pinte, Mattot, et al. [231]. They have shown that Egf17 (also known as VE-statin) is a secreted protein expressed by endothelial cells in normal tissues, but also by cancer cells in some human tumors. Increased levels of Egf17 is associated with high grade tumors and those that expressed high levels of Egf17 had poor infiltration by immune cells and had reduced levels of immunostimulatory cytokines, such as, IFN $\gamma$ and IL-12. They also had fewer endothelial adhesion molecules (vascular cell adhesion molecule $1<\mathrm{VCAM}-1>$ and intercellular adhesion molecule $1<\mathrm{ICAM}-1>$ ). Their conclusion is that tumors expressing Egf17 promote tumor progression and escape by reducing the expression of endothelial adhesion molecules that promote immune cell infiltration into the tumor microenvironment. This is just another unique method of many tumor escape mechanisms. Their studies indicated that the effect of Egfl7 on tumor growth and progression was indirect and that it promotes tumor escape from host immunity. They also confirmed that Egf17 provides an immunodeficient environment within human breast cancers. This explains why we saw decreased expression of ICAM-1 and VCAM-1 in our breast cancer specimens by IHC.

We believe another factor to be considered in this area of tumor immune evasion is the integrity of lymphocyte function associated antigen-1 (LFA-1) on lymphocytes in the heavily treated cancer patient. They not only often have very low total lymphocyte counts, but also their lymphocytes may have dysfunctional LFA-1. Even if the tumor endothelium has some expression of VCAM-1 and ICAM-1, the effector lymphocyte will not be able to have instantaneous extension of bent LFA-1 and thus tether and abruptly stop. Thus in marked tumor evasion, there could be both decreased adhesion molecules on the tumor endothelium and also patient dysfunctional effecttor lymphocytes. Lymphocytes with dysfunctional inactivated LFA-1.

\subsubsection{CD73 and $\mathrm{CD}_{4}^{+}$T-Helper Cells}

Jin, Fan, Wang, Thompson, et al. [232] have recently reported on CD73; and how its expression on tumor cells impairs antitumor T-cell responses. They state it is a very novel mechanism of tumor induced immune suppression. CD73, initially known as a lymphocyte differentiation antigen, and thought to function as a co-signaling molecule on T-lymphocytes and also as an adhesion molecule necessary for lymphocyte binding to endothelium. It is believed that the biological actions of CD73 are due to the regulated enzymatic phosphohydrolytic activity of extracellular nucleotides. This ecto-enzymatic cascade along with CD39 (ecto-ATPase) produces adenosine from ATP/AMP from inflamed and damaged cells into the tissue microenvironment [233]. The extracellular adenosine induces marked immunosuppressive effects and inhibits the activation and expansion of T-cells through the A2A (CA2Ar) adenosine receptor [234]. It has also been shown that adenosine generated from 
FoxP3 $\mathrm{CD}_{4}^{+}$Tregs through CD39/CD73 mediates immune suppression, and that CD73 is highly expressed on many human solid tumors $[235,236]$. The high expression of CD73 in tumors is associated with aggressiveness, progression, and shorter patient survival time [237,238]; and the A2AAR protects tumors from incoming effector antitumor T-cells [239]. The Jin group [232] showed that knockdown of CD73 on tumor cells by siRNA improved antitumor T-cell responses, both activation and effector functions; and also restored efficacy of adoptive T-cell therapy and long term survival in tumor bearing mice. They make the case for targeting enzymatic activity of CD73 as an important new approach to cancer immunotherapy.

Another factor involved in tumor immunosuppression and failure of cancer vaccines to produce a response is too few $\mathrm{CD}_{4}^{+}$helper T-cells in the tumor microenvironment. Ros and Shermon [240,241] have recently reported that $\mathrm{CD}_{4}^{+} \mathrm{T}$-cell help in the tumor milieu is required for attraction and the cytolytic function of $\mathrm{CD}_{8}^{+}$ T-lymphocytes. The production of IL-2 by tumor resident $\mathrm{CD}_{4}^{+}$T-cells greatly enhanced $\mathrm{CD}_{8}^{+}$T-cell proliferation and increased expression of granzyme B. They suggest that tumor specific $\mathrm{CD}_{4}^{+}$T-cells have an unique role post priming to promote tumor eradication. Their study revealed that an enhanced population of tumor specific $\mathrm{CD}_{8}^{+}$T-cells is a result of numerous effects of tumor specific $\mathrm{CD}_{4}^{+}$T-cells. The result of these $\mathrm{CD}_{4}^{+}$ T-cell effects is recruitment, proliferation, and survival of $\mathrm{CD}_{8}^{+} \mathrm{T}$-cells, thus aiding in reversing tumor immune suppression.

\subsubsection{Matrix Mellalloproteinases (MMPs)}

We would be derelict in this discussion of tumor immunosuppression, if we did not mention the very important role of MMPs in tumorigenesis and tumor immunosuppression. Extracellular proteolysis is important in mediating and maintaining tissue homeostasis. However, in cancer an altered proteolysis can lead to tissue remodeling, inflammation, tumor growth, tissue invasion, and metastasis. MMPs are the most prominent family of proteinases involved in tumorigenesis. The MMPs are modulators of the tumor microenvironment. They are involved in cancer cell migration, and extracellular matrix turnover, but they also control signaling pathways that regulate cell growth, angiogenesis and inflammation. All of these functions of MMPs in the tumor microenvironment make them an attractive target for cancer therapy.

Kessenbrock, Plaks, and Werb [242] have done a great review on MMPs and how they are important regulators of the tumor microenvironment. The MMPs were first described as a family of zinc-dependent endopeptidases by Gros and Lapiere almost a half century ago [243].
There are 23 MMPs expressed in humans, and they are categorized by their architectural features. Their chemistry and activation and inactivation functions are very complicated and involves a delicate balance. Sternlicht and Werb [244] have published a great paper on how MMPs regulate cell behavior. It is a detailed study of MMPs mechanism of action.

Closely related to MMPs are the so called ADAMs (disintegrin and metalloproteinase) which fulfill broad roles in function of fertilization, development, and cancer [245]. The function of MMPs in vivo depends on a critical local balance between them and their physiological inhibitors. The most important of the MMP physiological inhibitors are the tissue inhibitors of metalloproteinases (TIMPs). These are commonly expressed at tumor sites [246]. The expression in the tumor microenvironment of MMPs and their inhibitors is quite diverse, and although cancer cells from various tumors can express members of the MMP and ADAM families and also TIMPs, most of the MMP source of proteinases comes from the stromal cells infiltrating the tumor [247].

The function of the MMPs in the tumor microenvironment is diverse and complex, but we will try to mention some of the more important ones involved in tumor escape. ROS in tumors can influence the function of MMPs and the inflammatory responses at tumor sites generates large amounts of ROS produced by activated neutrophils and macrophages, and Rupp et al. [248] have shown that the binding of MMP-2 to integrin $\alpha_{v} \beta_{3}$ via its hemopexin domain is crucial for mesenchymal cell invasive activity. Several investigators [249-251] have shown that high local concentration of active MMP-14 on the cell membrane of metastatic cancer cells play very important roles in cell migration. It is now known that mechanical forces contribute to tumor progression [252] probably by modulating proteolysis of the ECM. These forces unwind the conformation of MMP substrate proteins allowing cleavage and recognition by proteinases. Butcher et al. [252] reported that fibronectin is cleaved by several MMPs and that the mechanotranstructural unfolding of fibronectin might initiate proteolytic degradation of this MMP substrate. The progression of tumors is often characterized by more tissue stiffness, altered blood flow and increased interstitial fluid pressure. Thus, it is possible that mechanical mechanisms of mechanical force are regulatory factors of MMP function in the tumor microenvironment.

For more than 40 years MMPs have been implicated in cancer and the fact that MMP mediated ECM degradation leads to cancer cell invasion and metastasis was a guiding force of MMP research [253]. However, clinical trials of MMP inhibitors failed to increase the survival of cancer patients [254]. Therefore MMPs are more com- 
plex than thought and rather than just degrading physical barriers they also affect multiple signaling pathways that control biological processes and disease. MMPs also in some circumstances exhibit tumor suppressive effects and mediate a number of biological effects on these surrounding tissues.

MMPs can affect growth signals of cells and may be very involved in disrupting the balance between growth and antigrowth signals in the tumor microenvironment. They influence the functionality or bioavailability of multiple important regulatory growth factors. One such factor is TGF- $\beta$, which is exploited by the tumor, and is turned into a tumor promoting factor that increases invasion and metastasis [255]. The tumor cells often acquire nonresponsiveness to TGF- $\beta$, which suggest that MMP proteolytic effects selectively promoting stroma-mediated invasion and tumor metastasis. The ligands for the epidermal growth factor receptor (EGFR) are potent drivers of cell proliferation and are regulators of tissue homeostasis. Malfunction of molecules in this system is observed in breast cancer and other malignancies [256, 257]. Evidence has revealed a potential role of ADAM proteinases in the regulation of the EGFR pathway. Activation of EGFR results in the upregulation of MMP-9, which degrades E-cadherin, potent controller of many important cellular functions including cell differentiation and cell-cell adhesion. The association of MMP-9, EGFR, and E-cadherin probably play a role in ovarian cancer progression as MMP-9 and activated EGFR colocalize in specimens within a region of reduced E-cadherin. The cleavage of E-cadherin by MMP or ADAM proteinases definitely has an impact on cell proliferation.

The role of MMPs in regulating apoptosis is now becoming evident, and MMP function interferes with the induction of apoptosis in malignant cells probably by involving the cleavage of ligands or receptors that promote proapoptotic signals. Mitsiades et al. [258] showed that MMP-7 cleaves the Fas ligand from the surface of doxorubicin treated cancer cells which lowered the impact of chemotherapy by abrogating apoptosis. Schulte $e t$ al. [259] have shown that ADAM-10 may suppress apoptosis induction by cytotoxic lymphocytes via the degradation of Fas ligand, therefore disrupting the Fas recaptor-triggered cell death of target cells. More importantly, the proteolytic shedding of tumor-associated MHC class I-related proteins MICA and MICB by ADAM-17 may suppress NK cell mediated cytotoxicity toward cancer cells and could potentially interfere with a directed antitumor immune response [260].

MMPs also play a role in angiogenesis and lymphangiogenesis which contributes to tumor invasion and metastasis. Some of the major MMPs involved in cancer angiogenesis are MMP-2, -9 , and -14 and to some extent
MMP-1 and -7. MMP-9 plays a distinct role in angiogenesis by regulating the bioavailability of VEGF the most important inducer of tumor angiogenesis. MMP-9 is also required for vasculogenesis, as well as playing an important role in angiogenesis; and it could be a target for adjunct therapy to enhance the radiotherapy response of tumors [261]. Nakamura et al. [262] have shown by using MMP inhibitors that MMPs promote lymphangiogenesis which plays an important role in tumor biology. The inhibition of both angiogenesis and lymphangiogenesis reduces lymph node metastasis.

Tumors secrete soluble factors that contribute to a metastatic niche in distant organs. This takes place before dissemination of tumor cells and is termed the premetastatic niche. MMP-9 has proved to be critical for the formation of this metastatic niche, probably linked to its ability to liberate VEGF and thus support angiogenesis [263]. There is evidence that MMPs are major regulators of innate and acquired immunity. MMPs modulate the function of chemokines and cytokines which have consequences of immunoregulatory function in the tumor microenvironment [264]. There is new research evidence on the nonproteolytic function of MMPs which may explain why earlier clinical trials using inhibitors of MMP catalytic domains were unsuccessful as anticancer therapeutics. By knowing more about expression patterns, we may in the future be able to make better rational decisions about what combination of MMP inhibitors and anticancer drugs to use.

It would be very difficult to concisely summarize the molecular mechanisms described here on tumor escape mechanisms. Therefore, we recommend a tremendous review entitled "Tumor-Driven Evolution of Immunosuppressive Networks During Malignant Progression" published by Kim and colleagues [241]. It is so complete, well done, and covered a wide range of immunosuppressive networks that we believe it is worth quoting verbatim the introductory abstract as follows:

"Tumors evolve mechanisms to escape immune control by a process called immune editing, which provides a selective pressure in the tumor microenvironment that could lead to malignant progression. A variety of tumor-derived factors contribute to the emergence of complex local and regional immunosuppressive networks, including vascular endothelial growth factor, interleukin-10, transforming growth factor- $\beta$, prostaglandin $\mathrm{E}_{2}$, and soluble phosphatidylserine, soluble Fas, soluble Fas ligand, and soluble MHC class I-related chain A proteins. Although deposited at the primary tumor site, these secreted factors could extend immunosuppressive effects into the local lymph nodes and the spleen, promoting invasion and metastasis. Vascular endothelial growth factors play a key role in recruiting immature 
myeloid cells from the bone marrow to enrich the microenvironment as tumor-associated immature dendritic cells and tumor-associated macrophages. The understanding of the immunosuppressive networks that evolve is incomplete, but several features are emerging. Accumulation of tumor-associated immature dendritic cells may cause roving dendritic cells and $T$ cells to become suppressed by the activation of indoleamine 2,3-dioxygenase and arginase I by tumor-derived growth factors. Soluble phosphatidylserines support tumor-associated macrophages by stimulating the release of anti-inflammatory mediators that block antitumor immune responses. Soluble Fas, soluble FasL, and soluble MHC class I-related chain A proteins may help tumor cells escape cytolysis by cytotoxic $\mathrm{T}$ cells and natural killer cells, possibly by counterattacking immune cells and causing their death. In summary, tumor-derived factors drive the evolution of an immunosuppressive network which ultimately extends immune evasion from the primary tumor site to peripheral sites in patients with cancer."

Kim and team [241] also discuss in detail the clinical implications of disrupting the immunosuppressive networks, and present many tips and suggestions on how cancer immunotherapeutic protocols could be implemented to improve effector cytolytic T-cell function and at the same time disrupt the many mechanisms of immunosuppression. This review is well worth the reader's time, if they desire a great detailed presentation of tumor immunosuppression.

\section{Conclusions}

We are now at the end of this journey on the relationship of the tight partnership of tumor iron metabolism, mitochondrial dysfunction and tumor immunosuppression. These partners are interrelated and they promote and aid each other to promote growth, progression, metastasis, immunosuppression, with the ultimate outcome being death of the patient. It is only by understanding the complexity of these interwoven partners in cancer growth, that we will be able to design strategies to inhibit and disrupt these complicated mechanisms and thus prevent cancer progression and death. We can design attacks at all levels of the partnership and the combined approach will allow for better treatment results, with probably less toxicity and much better overall survival. The time is now for us to launch a specific multipronged attack and eliminate this dreaded and tragic disease.

The road traveled on this review has also convinced us that remarkably Warburg was pretty much right on target about the role of mitochondrial dysfunction in malignnancy. The evidence is accumulating every day. We will soon be presenting some exciting evidence that mitochondrial dysfunction not only plays a role in tumori- genesis, but it also contributes to aggressiveness and drug resistance. The future discoveries will only make it even more remarkable the contributions of Warburg, especially in the era he worked. This communication is a humble tribute to his great research and observations, and we honor and greatly appreciate his tremendous contributions.

\section{Acknowledgements}

We want to acknowledge the tremendous efforts of Dr. Xian-Peng Jiang, who contributed to much of our research presented in this communication.

We also want to thank Lisa Allen for her assistance in preparing this manuscript and illustrations. Without her help the task would have been almost impossible.

\section{REFERENCES}

[1] C. Hershkov, "Control of Disease by Selective Iron Depletion: A Novel Therapeutic Strategy Utilizing Iron Chelators," Baillière's Clinical Haematology, Vol. 7, No. 4, 1994, pp. 965-1000.

doi:10.1016/S0950-3536(05)80133-7

[2] J. L. Buss, B. T. Greene, J. Turner, F. M. Torti and S. V. Torti, "Iron Chelators in Cancer Chemotherapy," Current Topics in Medicinal Chemistry, Vol. 4, 2004, pp. 1623 1635. doi:10.2174/1568026043387269

[3] N. C. Andrews, "Disorders of Iron Metabolism," The New England Journal of Medicine, Vol. 342, 2000, p. 1293. doi:10.1056/NEJM200004273421716

[4] R. Cammack, Th. Jm. Wrigglesworth and H. Baum, "IronDependent Enzymes in Mammalian Systems in Iron Transport and Storage," In: P. Ponka, H. M. Schulman, and R. C. Wodworth, Eds., Iron Transport and Storage, CRC Press, Boca Baton, 1990, pp. 17-40.

[5] L. Thelander, A. Gräslund and M. Thelander, "Continued Presence of Oxygen and Iron Required for Mammalian Riobonucleotide Reductase: Possible Regulation Mechanism," Biochemical and Biophysical Research Communications, Vol. 110, No. 3, 1983, pp. 859-865. doi:10.1016/0006-291X(83)91040-9

[6] M. Thelander, A. Grasland and L. Thelander, "Subunit M2 of Mammalian Ribonucleotide Reductase," Journal of Biological Chemistry, Vol. 250, No. 5, 1985, pp. 2737- 2741.

[7] I. S. Trowbridge, R. A. Newman, D. L. Domingo and C. Sauvage, "Transferrin Receptors: Structure and Formation," Biochemical Pharmacology, Vol. 33, No. 6, 1984, pp. 925-932. doi:10.1016/0006-2952(84)90447-7

[8] R. D. Klausner, G. Ashwell, J. van Renswoude, J. B. Harford and K. R. Bridges, "Binding of Apotransferrin to K562 Cells: Explanation of the Transferrin Cycle," Proceedings of the National Academy of Sciences of the United States of America, Vol. 80, No. 8, 1983, pp. 22632266. doi:10.1073/pnas.80.8.2263

[9] D. R. Richardson and P. Ponka, "The Molecular Mecha- 
nisms of the Metabolism and Transport of Iron in Normal and Neoplastic Cells," Biochimica et Biophysica Acta, Vol. 1331, No. 1, 1997, pp. 1-40. doi:10.1016/S0304-4157(96)00014-7

[10] P. A. Seligman, R. B. Schleicher and R. H. Allen, "Isolation and Characterization of the Transferrin Receptor from Human Placenta," Journal of Biological Chemistry, Vol. 254, No. 20, 1979, pp. 9943-9946.

[11] H. G. Wada, P. E. Hass and H. H. Sussman, "Transferrin Receptor in Human Placental Brush Border Membranes. Studies on the Binding of Transferrin to Placental Membrane Vesicles and the Identification of a Placental Brush Border Glycoprotein with High Affinity for Transferrin," Journal of Biological Chemistry, Vol. 254, No. 24, 1979, pp. 12629-12635.

[12] A. H. Lazarus and M. G. Baines, "A Rapid and Efficient Microtechnique for the Analysis of functional Transferrin Receptors on Tumor Cells," Journal of Immunological Methods, Vol. 79, No. 2, 1985, pp. 213-221. doi:10.1016/0022-1759(85)90101-2

[13] J. E. Shindleman, A. E. Ortmeyer and H. H. Sussman, "Demonstration of the Transferrin Receptor in Human Breast Cancer Tissue. Potential Marker for Identifying Dividing Cells," International Journal of Cancer, Vol. 79, No. 3, 1981, pp. 329-334. doi:10.1002/ijc.2910270311

[14] F. W. Warner, R. Stjernholm and I. Cohn, "Electron Paramagnetic Resonance Investigation of High-Spin Iron (III) in Cancer," Medical Physics, Vol. 5, No. 2, 1978, pp. 100-106. doi:10.1118/1.594471

[15] F. W. Warner, M. Demanuelle, R. Stjernholm, I. Cohn and W. H. Baddley, "Response to Transferrin Bound Iron to Treatment of Rat Lymphosarcoma with Cis-Dichlorodiammine-Platinum (II), Journal of Clinical Hematology \& Oncology, Vol. 7, 1977, pp. 180-189.

[16] R. L. Elliott, M. C. Elliott, F. Wang and J. F. Head, "Breast Carcinoma and the Role of Iron Metabolism: A Cytochemical, Tissue Culture, and Ultrastructural Study," Annals of the New York Academy of Sciences, Vol. 698, 1993, pp. 159-166. doi:10.1111/j.1749-6632.1993.tb17204.x

[17] R. L. Elliott, R. Stjernholm and M. C. Elliott, "Preliminary Evaluation of Platinum Transferrin (MPTC-63) as A Potential Nontoxic Treatment for Breast Cancer," Cancer Detection and Prevention, Vol. 12, No. 1-6, 1988, pp. 469480.

[18] S. I. Shpyleva, V. P. Tryndyak, O. Kovalchuk, A. Starlard-Davenport, V. F. Chekhun, F. A. Beland and I. P. Pogribny, "Role of Ferritin Alterations in Human Breast Cancer Cells," Breast Cancer Research and Treatment, Vol. 126, No. 1, 2011, pp. 63-71. doi:10.1007/s10549-010-0849-4

[19] A. Alkhateeb and J. Conner, "Ferritin Binds Breast Cancer Cells and Tissue, and Promotes Proliferation Independently of Iron Content," Cancer Research, Vol. 71, No. 8, 2011, p. 1108 .

[20] Y. Cheng, O. Zak, P. Aisen, S. C. Harrison and T. Waltz, "Structure of the Human Transferrin Receptor-Transferrin Complex," Cell, Vol. 116, No. 4, 2004, pp. 565-576.

\section{doi:10.1016/S0092-8674(04)00130-8}

[21] T. R. Daniels, T. Delgado, J. A. Rodriquez, G. Helgera, and M. L. Penichet, "The Transferrin Receptor Part 1: Biology and Targeting with Cytotoxic Antibodies for the Treatment of Cancer," Clinical Immunology, Vol. 121, No. 2, 2006, pp. 144-158. doi:10.1016/j.clim.2006.06.010

[22] T. R. Daniels, T. Delgado, G. Helguera and M. L. Penichet, "The Transferrin Receptor Part II: Targeted Delivery of Therapeutic Agents into Cancer Cells," Clinical Immunology, Vol. 121, No. 2, 2006, pp. 159-176.

[23] T. R. Daniels, E. Ortiz-Sanchez, R. Luria-Perez, R. Quintero, G. Helguera, B. Bonavida, O. Martinez-Maza and M. L. Penichet, "An Antibody-Based Multifaceted Approach Targeting the Human Transferrin Receptor for the Treatment of B-Cell Malignancies," Journal of Immunotherapy, Vol. 34, No. 6, 2011, pp. 500-508. doi:10.1097/CJI.0b013e318222ffc8

[24] H. O. Habashy, D. G. Powe, C. M. Staka, E. A. Rakha, G. Ball, A. R. Green, M. Aleskandarany, E. C. Paish, R. D. Macmillan, R. I. Nicholson, I. O. Ellis and J. M. W. Gee, "Transferrin Receptor (CD71) Is a Marker of Poor Prognosis in Breast Cancer and Can Predict Response to Tamoxifen," Breast Cancer Research and Treatment, Vol. 119, No. 2, 2010, pp. 283-293. doi:10.1007/s10549-009-0345-x

[25] D. C. Yang, X. P. Jiang, R. L. Elliott and J. F. Head, "Inhibition of Growth of Human Breast Carcinoma Cells by an Antisense Oligonucleotide Targeted to the Transferrin Receptor Gene," Anticancer Research, Vol. 21, No. 3B, 2001, pp. 1777-1787.

[26] X. P. Jiang, R. L. Elliott and J. F. Head, "Manipulation of Iron Transporter Genes Results in the Suppression of Human and Mouse Mammary Adenocarcinomas," Anticancer Research, Vol. 30, No. 3, 2010, pp. 759-765.

[27] F. Wang, R. L. Elliott and J. F. Head, "Inhibitory Effect of Deferoxamine Mesylate and Low Iron Diet on the 13762NF Rat Mammary Adenocarcinoma," Anticancer Research, Vol. 19, No. 1A, 1999, pp. 445-450.

[28] X. P. Jiang, F. Wang, D. C. Yang, R. L. Elliott and J. F. Head, "Induction of Apoptosis by Iron Depletion in the Human Breast Cancer MCF-7 Cell Line and 13762NF Rat Mammary Adenocarcinoma in Vivo," Anticancer Research, Vol. 22, No. 5, 2002, pp. 2685-2692.

[29] J. F. Head, F. Wang and R. L. Elliott, "Antineoplastic Drugs That Interfere with Iron Metabolism in Cancer Cells," Advances in Enzyme Regulation, Vol. 37, 1997, pp. 147-169. doi:10.1016/S0065-2571(96)00010-6

[30] E. Nemeth, M. S. Tuttle, J. Powelson, M. B. Vaughn, A. Donovan, D. M. Ward, T. Ganz and J. Kaplan, "Hepcidin Regulates Cellular Iron Efflux by Binding to Ferroportin and Inducing Its Internalization," Science, Vol. 306, No. 5704, 2004, pp. 2090-2093. doi:10.1126/science. 1104742

[31] D. R. Richardson, "Molecular Mechanisms of Iron Uptake by Cells and the Use of Iron Chelators for the Treatment of Caner," Current Medicinal Chemistry, Vol. 12, No. 23, 2005, pp. 2711-2729.

doi: $10.2174 / 092986705774462996$ 
[32] Y. Yu, Z. Kovacevic and D. R. Richardson, "Tuning Cell Cycle Regulation with an Iron Key," Cell Cycle, Vol. 6, 2007, pp. 1982-1994. doi:10.4161/cc.6.16.4603

[33] M. W. Hentze, M. U. Muckenthaler, B. Galy and C. Camaschella, "Two to Tango: Regulation of Mammalian Iron Metabolism," Cell, Vol. 142, No. 1, 2010, pp. 24-38. doi:10.1016/j.cell.2010.06.028

[34] C. Vecchi, G. Montosi, K. Zhang, I. Lamberti, S. A. Duncan, R. J. Kaufman and A. Pietrangelo, "ER Stress Controls Iron Metabolism through Induction of Hepcidin," Science, Vol. 325, No. 5942, 2009, pp. 877-880. doi:10.1126/science.1176639

[35] O. Weizer-Stern, K. Adamsky, O. Margalit, O. AshurFabian, D. Givolm N. Amariglio and G. Rechavi, "Hepcidin, a Key Regulator of iron metabolism, Is Transcriptionally Activated by p53," British Journal of Haematology, Vol. 138, No. 2, 2007, pp. 253-262. doi:10.1111/j.1365-2141.2007.06638.x

[36] T. Ganz and E. Nemeth, "Iron Sequestration and Anemia of Inflammation," Seminars in Hematology, Vol. 46, No. 4, 2009, pp. 387-393. doi:10.1053/j.seminhematol.2009.06.001

[37] D. R. Richardson, D. J. Lane, E. M. Becker, M. L. Huang, M. Whitnall, Y. Suryo Rahmanto, A. D. Sheftel and P. Ponka, "Mitochondrial Iron Trafficking and the Integration of Iron Metabolism between the Mitochondrion and Cytosol," Proceedings of the National Academy of the Sciences of the United States of America, Vol. 107, No. 24, 2010, pp. 10775-10782. doi:10.1073/pnas.0912925107

[38] A. Jacobs, "Low Molecular Weight Intracellular Iron Transport Compounds," Blood, Vol. 50, No. 3, 1977, pp. 433-439.

[39] G. R. Greenberg and M. M. Wintrobe, "A Labile Iron Pool," Journal of Biological Chemistry, Vol. 165, No. 1, 1946, pp. 397-398.

[40] P. Ponka, J. Borova, J. Neuwirt and O. Fuchs, "Mobilization of Iron from Reticulocytes. Identification of Pyridoxal Isonicotinozyl Hydraxone as a New Iron Chelating Agent," FEBS Letters, Vol. 97, No. 2, 1979, pp. 317-321.

[41] D. R. Richardson and K. Milnes, "The Potential of Iron Chelators of the Pyridoxal Isonicotinoyl Hydrazone Class as Effective Antiproliferative Agents II: The Mechanism of Action of Ligands Derived from Salicylaldehyde Benzoyl Hydrazone and 2-Hydroxy-1-Naphthylaldehyde Benzoyl Hydrazone," Blood, Vol. 89, 1997, pp. 3025-3038.

[42] A. D. Sheftel, A. S. Zhang, C. Brown, O. S. Shirihai and P. Ponka, "Direct Intraorganellar Transfer of Iron from Endosome to Mitochondrion," Blood, Vol. 110, No. 1, 2007, pp. 125-132. doi:10.1182/blood-2007-01-068148

[43] K. Isobe, Y. Isobe and T. Sakurami, "Cytochemical Demonstration of Transferrin in the Mitochondria of Immature Human Erythroid Cells," Acta Haematol, Vol. 65, No. 1, 1981, pp. 2-9. doi:10.1159/000207141

[44] A. S. Zhang, A. D. Sheftel and P. Ponka, "Intracellular Kinetics of Iron in Reticulocytes: Evidence for Endosome Involvement in Iron Targeting to Mitochondria," Blood,
Vol. 105, No. 1, 2005, pp. 368-375. doi:10.1182/blood-2004-06-2226

[45] P. Ponka, "Tissue-Specific Regulation of Iron Metabolism and Heme Synthesis: Distinct Control Mechanisms in Erythroid Cells," Blood, Vol. 89, 1997, pp. 1-25.

[46] B. J. Iacopetta and E. H. Morgasn, "The Kinetics of Transferrin Endocytosis and Iron Uptake from Transferrin in Rabbit Reticulocytes," Journal of Biological Chemistry, Vol. 258, 1983, pp. 9108-9115.

[47] D. W. Provance, Jr., C. R. Gourley, C. M. Silan, L. C. Cameron, K. M. Shokat, J. R. Goldenring, K. Shah, P. G. Gillespie and J. A. Mercer, "Chemical-Genetic Inhibition of a Sensitized Mutant Myosin vb Demonstrates a Role in Peripheral-Percentriolar Membrance Traffic," Proceedings of the National Academy of the Sciences of the United States of America, Vol. 101, No. 7, 2004, pp. 18681873. doi:10.1073/pnas.0305895101

[48] J. E. Lim, O. Jin, C. Benett, K. Morgan, F. Wang, C. C. Trenor $3^{\text {rd }}$, M. D. Fleming and N. C. Andrews, "A Mutation in Sec 15I1 Causes Anemia in Hemoglobin Deficit (hbd) Mice," Nature Genetics, Vol. 37, No. 11, 2005, pp. 1270-1273. doi:10.1038/ng1659

[49] A. S. Zhang, A. D. Sheftel and P. Ponka, "The Anemia of "Haemoglobin-Deficit (hbd/hbd) Mice Is Caused by a Defect in Transferrin Cycling," Experimental Hematology, Vol. 34, No. 5, 2006, pp. 593-598.

doi:10.1016/j.exphem.2006.02.004

[50] K. Strebhardt and A. Ullrich, "Paul Ehrlich's Magic Bullet Concept: 100 Years of Progress," Nature Reviews Cancer, Vol. 8, 2008, pp. 473-480. doi:10.1038/nrc2394

[51] O. Warburg, F. Wind and E. Negleis, "On the Metabolism of Tumors in the Body," In: O. Warburg, Ed., The Metabolism of Tumours, Constable, Princeton, 1930, pp. 254-270.

[52] O. Warburg, "On the Origin of Cancer Cells," Science, Vol. 123, No. 3191, 1956, pp. 309-314. doi:10.1126/science.123.3191.309

[53] E. Gottlieb and I. P. Tomlinson, "Mitochondrial Tumor Suppressors: A Genetic and Biochemical Update," Nature Reviews Cancer, Vol. 5, No. 11, 2005, pp. 857-866. doi:10.1038/nrc1737

[54] J. S. Carew and P. Huang, "Mitochondrial Defects in Cancer," Molecular Cancer, Vol. 1, 2002, p. 9. doi:10.1186/1476-4598-1-9

[55] K. Polyak, Y. Li, H. Zhu, C. Lengauer, J. K. Wilson, S. D. Markowitz, M. A. Trush, K. W. Kinzler and B. Vogelstein, "Somatic Mutations of the Mitochondrial Genome in Human Colorectal Tumors," Nature Genetics, Vol. 20, No. 3, 1998, pp. 291-293. doi:10.1038/3108

[56] J. A. Petros, A. K. Baumann, E. Ruiz-Pesini, M. B. Amin, C. Q. Sun, J. Hall, S. Lim, M. M. Issa, W. D. Flanders, S. H. Hosseini, F. F. Marshall and D. C. Wallace, "mtDNA Mutations Increase Tumorigenicity in Prostate Cancer," Proceedings of the National Academy of the Sciences of the United States of America, Vol. 102, No. 3, 2005, pp. 719-724. doi:10.1073/pnas.0408894102

[57] Y. Shidara, K. Yamagata, T. Kanamori, K. Nakano, J. Q. 
Kwong, G. Manfredi, H. Oda and S. Ohta, "Positive Contribution of Pathogenic Mutations in the Mitochondrial Genome to the Promotion of Cancer by Prevention from Apoptosis," Cancer Research, Vol. 65, 2005, pp. 16551663. doi:10.1158/0008-5472.CAN-04-2012

[58] M. A. Selak, S. M. Armour, E. D. MacKenzie, H. Boulahbel, D. G. Watson, K. D. Mansfield, Y. Pan, M. C. Simon, C. B. Thompson and E. Gottleib, "Succinate Links TCA Cycle Dysfunction to Oncogenesis by Inhibiting HIF-Alpha Prolyl Hydroxylase," Cancer Cell, Vol. 7, 2005, pp. 77-85. doi:10.1016/j.ccr.2004.11.022

[59] D. D. Newmeyer and S. Ferguson-Miller, "Mitochondria: Releasing Power for Life and Unleashing the Machineries of Death," Cell, Vol. 112, No. 4, 2003, pp. 481-490. doi:10.1016/S0092-8674(03)00116-8

[60] M. Karbouski and R. J. Youle, "Dynamics of Mitochondrial Morphology in Healthy Cells and during Apoptosis," Cell Death and Differentiation, Vol. 10, 2003, pp. 870-880. doi: $10.1038 /$ sj.cdd. 4401260

[61] J. Downward, "Cell Biology: Metabolism Meets Death," Nature, Vol. 424, No. 6951, 2003, pp. 896-897. doi:10.1038/424896a

[62] J. E. Ricci, C. Munoz-Pinedo, P. Fitzgerald, B. BaillyMaitre, G. A. Perkins, N. Yadava, I. E. Scheffler, M. H. Ellisman and D. R. Green, "Disruption of Mitochondrial Function during Apoptosis Is Mediated by Caspase Cleavage of the p75 Subunit of Complex I of the Electron Transport Chain," Cell, Vol. 117, No. 6, 2004, pp. 773786. doi:10.1016/j.cell.2004.05.008

[63] T. Albayrak, V. Scherhammer, N. Schoenfeld, E. Braziulis, T. Mund, M. K. Bauer, I. E. Scheffler and S. Grimm, "The Tumor Suppressors cybL, a Component of the Respiratory Chain Mediates Apoptosis Induction," Molecular Biology of the Cell, Vol. 14, No. 8, 2003, pp. 3082-3096. doi:10.1091/mbc.E02-10-0631

[64] T. Ishii, K. Yasuda, A. Akatsuka, O. Hino, P. S. Hartman, and N. Ishii, "A Mutation in the SDHC Gene of Complex II Increases Oxidative Stress, Resulting in Apoptosis and Tumorigenesis," Cancer Research, Vol. 65, No. 1, 2005, pp. 203-209.

[65] R. A. Gatenby and R. J. Gillies, "Why Do Cancers Have High Aerobic Glycolysis?" Nature Reviews Cancer, Vol. 4, 2004, pp. 891-899. doi:10.1038/nrc1478

[66] J. W. Kim and C. V. Dang, "Multifaceted Roles of Glycolytic Enzymes," Trends in Biochemical Sciences, Vol. 30, No. 3, 2005, pp. 42-150. doi:10.1016/j.tibs.2005.01.005

[67] N. Majewski, V. Nogueira, P. Bhaskar, P. E. Coy, J. E. Skeen, K. Gottlob, N. S. Chandel, C. B. Thompson, R. B. Robey and N. Hay, "Hexokinase-Mitochondria Interaction Mediated by AKT Is Required to Inhibit Apoptosis in the Presence or Absence of Box and Bak," Molecular Cell, Vol. 16, No. 5, 2004, pp. 819-830. doi:10.1016/j.molcel.2004.11.014

[68] P. Storz, "Reactive Oxygen Species in Tumor Progression," Frontiers in Bioscience, Vol. 10, 2005, pp. 18811896. doi:10.2741/1667
[69] G. L. Semenza, "HIF-1 and Tumor Progression: Pathophysiology and Therapeutics," Trends in Molecular Medicine, Vol. 8, No. 4, 2002, pp. 62-67. doi:10.1016/S1471-4914(02)02317-1

[70] K. L. Covello and M. C. Simon, "HIFs, Hypoxia, and Vascular Development," Current Topics in Developmental Biology, Vol. 62, 2004, pp. 37-54. doi:10.1016/S0070-2153(04)62002-3

[71] H. Yeo and S. Roman, "Pheochromocytoma and Functional Paraganglioma," Current Opinion in Oncology, Vol. 17, No. 1, 2005, pp. 13-18. doi:10.1097/01.cco.0000147900.12325.d9

[72] J. Lopez-Barneo, R. del Toro, K. L. Levitsky, M. D. Chiara and P. Ortega-Saenz, "Regulation of Oxygen Sensing by Iron Channels," Journal of Applied Physiology, Vol. 96, No. 3, 2004, pp. 1187-1195. doi:10.1152/japplphysiol.00929.2003

[73] S. Vanharanta, M. Buchta, S. R. McWhinney, S. K. Virta, M. Peczkowska, C. D. Morrison, R. Lehtonen, A. Januszewiez, H. Jarvinen, M. Juhola, J. P. Mecklin, E. Pukkala, R. Herva, M. Kiuru, N. N. Nupponen, L. A. Aaltonen, H. P. Neumann and C. Eng, "Early-Onset Renal Cell Carcinoma as a Novel Extraparaganglial Component of SDHBAssociated Heritable Paraganglioma," The American Society of Human Genetics, Vol. 74, No. 1, 2004, pp. 153159. doi:10.1086/381054

[74] W. Y. Kim and W. G. Kaelin, "Role of VHL Gene Mutation in Human Cancer," Journal of Clinical Oncology, Vol. 22, No. 24, 2004, pp. 4991-5004. doi:10.1200/JCO.2004.05.061

[75] A. L. Harris, "Hypoxia-A Key Regulatory Factor in Tumor Growth," Nature Reviews Cancer, Vol. 2, No. 1, 2002, pp. 38-47. doi:10.1038/nrc704

[76] G. L. Semenza, "Targeting HIF-1 for Cancer Therapy," Nature Reviews Cancer, Vol. 3, 2003, pp. 721-732. doi:10.1038/nrc1187

[77] R. L. Elstrom, D. E. Bauer, M. Buzzai, R. Karnauskas, M. H. Harris, D. R. Plas, H. Zhuang, R. M. Cinalli, A. Alavi, C. M. Rudin and C. B. Thompson, "Akt Stimulates Aerobic Glycolysis in Cancer Cells," Cancer Research, Vol. 64, 2004, pp. 3892-3899. doi:10.1158/0008-5472.CAN-03-2904

[78] B. Blouw, H. Song, T. Tihan, J. Bosze, N. Ferrar, H. P. Gerber, R. S. Johnson and G. Bergers, "The Hypoxic Response of Tumors Is Dependent on Their Microenvironment," Cancer Cell, Vol. 4, No. 2, 2003, pp. 133-146. doi:10.1016/S1535-6108(03)00194-6

[79] Y. Ma, R. K. Bai, R. Trieu and L. J. Wong, "Mitochondrial Dysfunction in Human Breast Cancer Cells and Their Transmitochondrial Cybrids," Biochimica et Biophysica Acta, Vol. 1797, No. 1, 2010, pp. 29-37. doi:10.1016/j.bbabio.2009.07.008

[80] C. Frezza, P. J. Pollard and E. Gottlieb, "Inborn and Acquired Metabolic Defects in Cancer," Journal of Molecular Medicine, Vol. 89, No. 3, 2011, pp. 213-220. doi:10.1007/s00109-011-0728-4

[81] E. D. MacKenzie, M. A. Selak, D. A. Tennant, L. J. 
Payne, S. Crosby, C. M. Frederiksen, D. G. Watson and E. Gottlieb, "Cell-Permeating Alpha-Ketoglutarate Derivatives Alleviate Pseudohypoxia in Succinate Dehydrogenase-Deficient Cells," Molecular and Cellular Biology, Vol. 27, No. 9, 2007, pp. 3282-3289. doi:10.1128/MCB.01927-06

[82] A. M. Porcelli, A. Ghelli, C. Ceccarelli, M. Lang, G. Canacchi, M. Capristo, L. F. Pennisi, I. Morra, E. Ciccarelli, A. Melcarne, A. Bartoletti-Stella, N. Salfi, G. Tallini, A. Martinuzzi, V. Carelli, M. Attimonelli, M. Rugolo, G. Romeo and G. Gasparre, "The Genetic and Metabolic Signature of Oncocytic Transformation Implicates HIF1alpha Destabilization," Human Molecular Genetics, Vol. 19, No. 6, 2010, pp. 1019-1032.

doi:10.1093/hmg/ddp566

[83] E. Kirches, "Mitochondrial and Nuclear Genes of Mitochondrial Components in Cancer," Current Genomics, Vol. 10, No. 2009, pp. 281-293. doi: $10.2174 / 138920209788488517$

[84] V. Fogg, N. J. Lanning and J. P. MacKeigan, "Mitochondria in Cancer: At the Crossroads of Life and Death," Chinese Journal of Cancer, Vol. 30, No. 8, 2011, pp. 526539.

[85] W. B. Coley, "Contribution to the Knowledge of Sarcoma," Annals of Surgery, Vol. 14, No. 3, 1891, pp. 199220. doi:10.1097/00000658-189112000-00015

[86] R. L. Elliott, "Combination Cancer Immunotherapy Expanding Paul Ehrlich's Magic Bullet Concept," Surgical Oncology, Vol. 21, No. 1, 2012, pp. 53-55. doi:10.1016/j.suronc.2010.02.002

[87] R. L. Elliott and J. F. Head, "Host Immunity Ignored in Clinical Oncology: A Medical Opinion," Cancer Biotherapy \& Radiopharmaceuticals, Vol. 20, No. 2, 2005, pp. 123-125. doi:10.1089/cbr.2005.20.123

[88] R. L. Elliott, "Cancer Immunotherapy More than Vaccines "Psychoneuro-Immunooncology: Cancer, the Host, and the Surgeon," Journal of Cancer Therapy, Vol. 2, No. 3, 2011, pp. 401-407. doi:10.4236/jct.2011.23055

[89] G. P. Dunn, A. T. Bruce, H. Ikeda, L. J. Old and R. D. Schreiber, "Cancer Immunoediting from Immunosurveillance to Tumor Escape," Nature Immunology, Vol. 3, 2002, pp. 991-998. doi:10.1038/ni1102-991

[90] R. Kim, M. Emi and K. Tanabe, "Cancer Immunoediting from Immune Surveillance to Immune Escape," Immunology, Vol. 121, No. 1, 2007, pp. 1-14. doi:10.1111/j.1365-2567.2007.02587.x

[91] M. Urosevic and R. Dummer, "Human Leukocyte Antigen-G and Cancer Immunoediting," Cancer Research, Vol. 68, No. 3, 2008, pp. 627-630. doi:10.1158/0008-5472.CAN-07-2704

[92] M. Urosevic and R. Dummer, "HLA-G and IL-10 Expression in Human Cancer-Different Stories with the Same Message," Seminars in Cancer Biology, Vol. 13, No. 5, 2003, pp. 337-342. doi:10.1016/S1044-579X(03)00024-5

[93] U. Feger, E. Tolosa, T. H. Huang, A. Waschbish, T. Biedermann, A. Melms and H. Wiendl, "HLA-G Expres- sion Defines a Novel Regulatory T-Cell Subset Present in Human Peripheral Blood and Sites of Inflammation," Blood, Vol. 110, No. 2, 2007, pp. 568-577. doi:10.1182/blood-2006-11-057125

[94] N. Rouas-Freiss, P. Moreau, S. Ferrone and E. D. Carosella, "HLA-G Proteins in Cancer: Do They Provide Tumor Cells with an Escape Mechanism?" Cancer Research, Vol. 65, 2005, pp. 10139-10144. doi:10.1158/0008-5472.CAN-05-0097

[95] P. Tripathi and S. Agrawal, "Non-Classical HLA-G Antigen and Its Role in the Cancer Progression," Cancer Investigation, Vol. 24, No. 2, 2006, pp. 178-186. doi:10.1080/07357900500524579

[96] R. L. Elliott, X. P. Jiang, J. T. Phillips, B. G. Barnett and J. F. Head, "Human Leukocyte Antigen G Expression in Breast Cancer: Role in Immunosuppression," Cancer Biotherapy \& Radiopharmaceuticals, Vol. 26, No. 2, 2011, pp. 153-157. doi:10.1089/cbr.2010.0924

[97] I. J. Elenkov, R. L. Wilder, G. P. Chrousos and E. S. Vizi, "The Sympathetic Nerve-An Integrative Interface between Two Supersystems: The Brain and the Immune System," Pharmacological Reviews, Vol. 52, No. 4, 2000, pp. 595-638.

[98] S. Ben-Eliyahu, "The Promotion of Tumor Metastasis by Surgery and Stress: Immunological Basis and Implications for Psychoneuroimmunology," Brain, Behavior, and Immunity, Vol. 17, No. 1, 2003, pp. 27-36. doi:10.1016/S0889-1591(02)00063-6

[99] R. L. Elliott, J. F. Head and J. L. McCoy, "Comparison of Estrogen and Progesterone Receptors Status to Lymphocyte Immunity against Tumor Antigens in Breast Cancer Patients," Breast Cancer Research and Treatment, Vol. 30, No. 3, 1994, pp. 299-304. doi:10.1007/BF00665971

[100] J. F. Head, F. Wang, R. L. Elliott and J. L. McCoy, “Assessment of Immunologic Competence and Host Reactivity against Tumor Antigens in Breast Cancer Patients: Prognostic Value and Rational of Immunotherapy Development," Annals of the New York Academy of Sciences, Vol. 609, 1993, pp. 340-342. doi:10.1111/j.1749-6632.1993.tb44024.x

[101] E. Faist, C. Schinkel and S. Zimmer, "Update on the Mechanisms of Immune Suppression of Injury and Immune Modulations," World Journal of Surgery, Vol. 20, No. 4, 1996, pp. 454-459. doi:10.1007/s002689900071

[102] R. Melamed, E. Rosenne, K. Sakhar, Y. Schwartz, N. Abudarham and S. Ben-Eliyahu, "Marginating Pulmonary-NK Activity and Resistance to Experimental Tumor Metastasis: Suppression by Surgery and the Prophylactic Use of a Beta-Adrenergic Antagonist and a Prostaglandin Synthesis Inhibitor," Brain, Behavior, and Immunity, Vol. 19, No. 2, 2005, pp. 114-126. doi:10.1016/j.bbi.2004.07.004

[103] J. Wu and L. L. Lanier, "Natural Killer Cells and Cancer," Advances in Cancer Research, Vol. 90, 2003, pp. 127-156. doi:10.1016/S0065-230X(03)90004-2

[104] B. L. Andersen, W. B. Farrar, D. Golden-Kreutz, L. A. Kutz, R. MacCallum, M. E. Courtney and R. Glaser, "Stress and Immune Responses after Surgical Treatment 
for Regional Breast Cancer," Journal of the National Cancer Institute, Vol. 90, No. 1, 1998, pp. 30-36. doi:10.1093/inci/90.1.30

[105] A. Taketomi, M. Shimada, K. Shirabe, K. Kajiyama, T. Gion and K. Sugimachi, "Natural Killer Cell Activity in Patients with Hepatocellular Carcinoma: A New Prognostic Indicator after Hepatectomy," Cancer, Vol. 83, No. 1, 1998, pp. 58-63.

doi:10.1002/(SICI)1097-0142(19980701)83:1<58::AID-C NCR8 $>3.0 . \mathrm{CO} ; 2-\mathrm{A}$

[106] H. Takeuchi, Y. Maehara, E. Tokunaga, T. Koga, Y. Kakeji and K. Sugimachi, "Prognostic Significance of Natural Killer Cell Activity in Patients with Gastric Carcinoma: A Multivariate Analysis," The American Journal of Gastroenterology, Vol. 96, No. 2, 2001, pp. 574-578. doi:10.1111/j.1572-0241.2001.03535.X

[107] A. Riesco, "Five-Year Cancer Care: Relation to Total Amount of Peripheral Lymphocytes and Neutrophils," Cancer, Vol. 25, No. 1, 1970, pp. 135-140. doi:10.1002/1097-0142(197001)25:1<135::AID-CNCR28 20250120>3.0.CO;2-9

[108] L. A. Fumagalli, J. Vinke, W. Hoff, E. Ypma, F. Brivio and A. Nespoli, "Lymphocyte Counts Independently Predict Overall Survival in Advanced Cancer Patients: A Biomarker for IL-2 Immunotherapy," Journal of Immunotherapy, Vol. 26, No. 5, 2003, pp. 394-402. doi:10.1097/00002371-200309000-00002

[109] X. Jiang, K. Hsu, J. F. Head and R. L. Elliott, "Iron Inhibits the Cytotoxicity of Nitric Oxide and the Associated Cytolysis by Natural Killer Cells of MCF-7 Human Breast Cancer Cells [Abstract]," Proceedings of the American Association for Cancer Research, Vol. 47, 2006, p. 629.

[110] J. F. Head, X. P. Jiang and R. L. Elliott, "Cancer Immunosuppression: The Role of Tumor Iron Metabolism," Personal Data to Be Published.

[111] R. N. Watts and D. R. Richardson, "The Mechanism of Nitrogen Monoxide (NO)-Mediated Mobilization from Cells: NO Intercepts Iron before Incorporation into Ferritin and Indirectly Mobilizes Iron from Ferritin in a Glutathione-Dependent Manner," European Journal of Biochemistry, Vol. 269, No. 14, 2002, pp. 3383-3392. doi:10.1046/j.1432-1033.2002.02987.x

[112] D. R. Richardson and P. Ponka, "The Molecular Mechanisms of the Metabolism and Transport of Iron in Norm and Neoplastic Cells," Biochimica et Biophysica Acta, Vol. 1331, No. 1, 1997, pp. 1-40. doi:10.1016/S0304-4157(96)00014-7

[113] J. C. Drapier and J. B. Hibbs Jr., "Murine Cytotoxic Activated Macrophages Inhibit Aconitase in Tumor Cells. Inhibition Involves the Iron-Sulfur Prosthetic Group and is Reversible," Journal of Clinical Investigation, Vol. 78, 1986, pp. 790-797. doi:10.1172/JCI112642

[114] J. C. Drapier and J. B. Hibbs Jr., "Differentiation of Murine Macrophages to Express Non-Specific Cytotoxicity for Tumor Cells Results in L-Arginine Dependent Inhibition of Mitochondrial Iron-Sulfur Enzymes in the Macrophage Effector Cells," Journal of Immunology, Vol. 140,
No. 8, 1988, pp. 2829-2838.

[115] Y. Henry, C. Ducrocg, J. C. Drapier, D. Servent, C. Pellat and A. Guissani, "Nitric Oxide, a Biological Effector Molecule. Electron Paramagnetic Resonance Detection of Nitrosyl-Iron-Protein Complexes in Whole Cells," European Biophysics Journal, Vol. 20, No. 1, 1991, pp. 1-15.

[116] A. Gupte and R. J. Mumper, "Elevated Copper and Oxidative Stress in Cancer Cells as a Target for Cancer Treatment," Cancer Treatment Reviews, Vol. 35, No. 1, 2009, pp. 32-46. doi:10.1016/j.ctrv.2008.07.004

[117] W. Yu, J. Wong, D. B. Lovejoy, D. S. Kalinowski and D. R. Richardson, "Chelators at the Cancer Coalface: Desferrioxamine to Triapine and Beyond," Clinical Cancer Research, Vol. 12, 2006, pp. 6876-6883. doi:10.1158/1078-0432.CCR-06-1954

[118] P. M. Pahl and L. D. Horwitz, "Cell Permeable Iron Chelators as Potential Cancer Chemotherapeutic Agents," Cancer Investigation, Vol. 23, No. 8, 2005, pp. 683-691. doi:10.1080/07357900500359976

[119] D. B. Lovejoy, P. J. Jansson, U. T. Brunk, J. Wong, P. Ponka and D. R. Richardson, "Antitumor Activity of Metal-Chelating Compound Dp44mT Is Mediated by Formation of a Redox-Active Copper Complex That Accumulates in Lyposomes," Cancer Research, Vol. 71, No. 17, 2011, pp. 5871-5880. doi:10.1158/0008-5472.CAN-11-1218

[120] J. Tian, D. M. Peehl, W. Zheng and S. J. Knox, "AntiTumor and Radiosensitization Activities of the Iron Chelator HDp44mT Are Mediated by Effects on intracellular Redox Status," Cancer Letters, Vol. 298, No. 2, 2010, pp. 231-237. doi:10.1016/j.canlet.2010.07.010

[121] V. A. Rao, J. Zhang, S. R. Klein, P. Espandiari, A. Knapton, J. S. Dickey, E. Herman and E. B. Shacter, "The Iron Chelator Dp44mT Inhibits the Proliferation of Cancer Cells but Fails to Protect from Doxorubicin-Induced Cardiotoxicity in Spontaneously Hypersensitive Rats," Cancer Chemotherapy and Pharmacology, Vol. 68, No. 5, 2011, pp. 1125-1134. doi:10.1007/s00280-011-1587-y

[122] V. A. Rao, S. R. Klein, K. K. Agama, E. Toyoda, N. Adachi, Y. Pomonier and E. B. Shacter, "The Iron Chelator Dp44mT Causes DNA Damage and Selective Inhibition of Topoisomerase IIalpha in Breast Cancer Cells," Cancer Research, Vol. 69, 2009, pp. 948-957. doi:10.1158/0008-5472.CAN-08-1437

[123] P. J. Jansson, P. C. Sharpe, P. V. Bernhardt and D. R. Richardson, "Novel Thiosemicarbazones of the ApT and DpT Series and Their Copper Complexes: Identification of Pronounced Redox Activity and Characterization of Their Antitumor Activity," Journal of Medicinal Chemistry, Vol. 53, No. 15, 2010, pp. 5759-5769. doi:10.1021/jm100561b

[124] R. B. Seth, L. Sun, C. Ea and Z. J. Chem, "Identification and Characterization of MAVS, a Mitochondrial Antiviral Signaling Protein That Activates NF- $\kappa \mathrm{B}$ and IRF3," Cell, Vol. 122, No. 5, 2005, pp. 669-682. doi:10.1016/j.cell.2005.08.012

[125] L. G. Xu, Y. Y. Wang, K. J. Han, L. Y. Li, Z. Zhai and H. B. Shu, "VISA Is an Adapter Protein Required for Vi- 
rus-Triggered INF-Beta Signaling," Molecular Cell, Vol. 19, No. 6, 2005, pp. 727-740. doi:10.1016/i.molcel.2005.08.014

[126] A. Mantovani, P. Allavena, A. Sica and F. Balkwill, "Cancer-Related Inflammation," Nature, Vol. 454, 2008, pp. 436-444. doi:10.1038/nature07205

[127] R. Catlet-Facone, T. H. Landowski, M. M. Oshiro, J. Turkson, A. Levitzki, R. Savino, G. Ciliberto, L. Moscinski, J. L. Fernandez-Luna, G. Nunez, W. S. Dalton and R. Jove, "Constitutive Activation of Stat3 Signaling Confers Resistance to Apoptosis in Human U266 Myeloma Cells," Immunity, Vol. 10, No. 1, 1999, pp. 105-115. doi:10.1016/S1074-7613(00)80011-4

[128] M. Kujawski, M. Kortylewski, H. Lee, A. Herrmann, H. Kay and H. Yu, "Stat3 Mediates Myeloid Cell-Dependent Tumor Angiogenesis in Mice," The Journal of Clinical Investigation, Vol. 118, No. 10, 2008, pp. 3367-3377. doi:10.1172/JCI35213

[129] M. Kortylewski, M. Kujawski, H. Lee, Y. Liu, T. Harris, C. Drake, D. Pardoll and H. Yu, "Regulation of the IL-23 and IL-12 Balance by Stat3 Signaling in the Tumor Microenvironment," Cancer Cell, Vol. 15, No. 2, 2009, pp. 114-123. doi:10.1016/j.ccr.2008.12.018

[130] H. Yu, D. Pardoll and R. Jove, "STATs in Cancer Inflammation and Immunity: A Leading Role for STAT3," Nature Reviews Cancer, Vol. 9, No. 11, 2009, pp. 798809. doi:10.1038/nrc2734

[131] E. Pikarsky, R. M. Porat, I. Stein, R. Abramovitch, S. Amit, S. Kasem, E. Gutkovich-Pyest, S. Urieli-Shoval, E. Galun and Y. Ben-Neriah, "NF-KappaB Functions as a Tumor Promoter in Inflammation-Associated Cancer," $\mathrm{Na}$ ture, Vol. 431, No. 7007, 2004, pp. 461-466. doi:10.1038/nature02924

[132] V. Baud and M. Karin, "Is NF-KappaB a Good Target for Cancer Therapy? Hopes and Pitfalls," Nature Reviews Drug Discovery, Vol. 8, No. 1, 2009, pp. 33-40. doi: $10.1038 / \mathrm{nrd} 2781$

[133] M. Karin and F. R. Greten, "NF-KappaB: Linking Inflammation and Immunity to Cancer Development and Progression," Nature Reviews Immunology, Vol. 5, No. 10, 2005, pp. 749-757. doi:10.1038/nri1703

[134] H. Yu, M. Kortylewski and D. Pardoll, "Crosstalk between Cancer and Immune Cells: Role of STAT3 in the Tumour Microenvironment," Nature Reviews Immunology, Vol. 7, No. 1, 2007, pp. 41-51. doi:10.1038/nri1995

[135] D. S. Basseres and A. S. Baldwin, "Nuclear Factor-KappaB and Inhibition of KappaB Kinase Pathways in Oncogenic Initiation and Progression," Oncogene, Vol. 25, 2006, pp. 6817-6830. doi:10.1038/sj.onc. 1209942

[136] M. Kortylewski, M. Kujawski, T. Wang, S. Wei, S. Zhang, S. Pilon-Thomas, G. Niu, H. Kay, J. Mule, W. G. Kerr, R. Jove, D. Pardoll and H. Yu, "Inhibiting STAT3 Signaling in the Hematopoietic System Elicits Multicomponent Anti-Tumor Immunity," Nature Medicine, Vol. 11, No. 12, 2005, pp. 1314-1321.

doi: $10.1038 / \mathrm{nm} 1325$
[137] G. Trinchieri, "Interleukin-12 and the Regulation of Innate Resistance and Adaptive Immunity," Nature Reviews Immunology, Vol. 2003, pp. 3133-3146.

[138] P. Cheng, C. A. Corzo, N. Luetteke, B. Yu, S. Nagaraj, M. M. Bui, M. Ortiz, W. Nacken, C. Sorg, T. Vogl, J. Roth and D. I. Gabrillovich, "Inhibition of Dendritic Cell Differentiation and Accumulation of Myeloid-Derived Suppressor Cells in Cancer Is Regulated by S100A9 Protein," The Journal of Experimental Medicine, Vol. 205, No. 10, 2008, pp. 2235-2249. doi:10.1084/jem.20080132

[139] L. Wang, T. Yi, M. Kortylewski, D. Pardoll, D. Zeng and H. Yu, "IL-17 Can Promote Tumor Growth through an IL-6-STAT3 Signaling Pathway," The Journal of Experimental Medicine, Vol. 206, No. 7, 2009, pp. 1457-1464. doi:10.1084/jem.20090207

[140] Y. Matsumura, T. Kobayashi, K. Ichiyama, R. Yoshida, M. Hashimoto, T. Takimoto, K. Tanaka, T. Chinen, T. Shichita, T. Wyss-Coray, K. Sato and A. Yoshimura, "Selective Expression of Foxp3-Positive Regulatory T Cells and Immunosuppression by Suppressors of Cytokine Signaling 3-Deficient Dendritic Cells," Journal of Immunotherapy, Vol. 179, 2007, pp. 2170-2179.

[141] S. Wu, K. J. Rhee, E. Albesiano, S. Rabizadeh, X. Wu, H. R. Yen, D. L. Huso, F. L. Brancati, E. Wick, F. Mc-Allister, F. Housseau, D. M. Pardoll and C. L. Sears, "A Human Colonic Commensal Promotes Colon Tumorigenesis via Activation of T Helper Type $17 \mathrm{~T}$ Cell Responses," Nature Medicine, Vol. 15, 2009, pp. 10161022. doi: $10.1038 / \mathrm{nm} .2015$

[142] Y. Huang, L. Lin, A. Shanker, A. Malhotra, L. Yang, M. M. Dikov and D. P. Carbone, "Resuscitating Cancer Immunosurveillance: Selective Stimulation of DLL1-Notch Signaling in T Cells Rescues T-Cell Function and Inhibits Tumor Growth," Cancer Research, Vol. 71, No. 19, 2011, pp. 6122-6131. doi:10.1158/0008-5472.CAN-10-4366

[143] A. E. Karnoub, A. B. Dash, A. P. Vo, A. Sullivan, M. W. Brooks, G. W. Bell, A. L. Richardson, K. Polyak, R. Tubo and R. A. Weinberg, "Mesenchymal Stem Cells within Tumour Stroma Promote Breast Cancer Metastasis," Nature, Vol. 449, 2007, pp. 557-563. doi:10.1038/nature06188

[144] S. K. Leivonen and V. M. Kahari, "Transforming Growth Factor-Beta Signaling in Cancer Invasion and Metastasis," International Journal of Cancer, Vol. 121, No. 10, 2007, pp. 2119-2124. doi:10.1002/ijc.23113

[145] A. L. Welm, "TGFbeta Primes Breast Tumor Cells for Metastasis," Cell, Vol. 133, No. 1, 2008, pp. 27-28. doi:10.1016/j.cell.2008.03.012

[146] P. Padua, X. H. F. Zhang, Q. Wang, C. Nadal, W. L. Gerald, R. R. Gomis and J. Massague, "TGFbeta Primes Breast Tumors for Lung Metastasis Seeding through Angiopoietin-Like 4," Cell, Vol. 133, No. 1, 2008, pp. 66-77. doi:10.1016/j.cell.2008.01.046

[147] H. Ikushima and K. Miyazono, "TGFbeta Signaling: A Complex Web in Cancer Progression," Nature Reviews Cancer, Vol. 10, No. 6, 2010, pp. 415-424. doi: $10.1038 / \mathrm{nrc} 2853$

[148] B. Bierie and H. L. Moses, "Tumor Microenvironment: 
TGFbeta: The Molecular Jekyll and Hyde of Cancer," Nature Reviews Cancer, Vol. 6, No. 7, 2006, pp. 506-520. doi:10.1038/nrc1926

[149] P. K. Singha, I. T. Yeh, M. A. Venhalachalam and P. Saikumar, "Transforming Growth Factor-Beta (TGFBeta)-Inducible Gene TMEPAI Coverts TGF-Beta from a Tumor Suppressor to a Tumor Promoter in Breast Cancer," Cancer Research, Vol. 70, No. 15, 2010, pp. 63776383. doi:10.1158/0008-5472.CAN-10-1180

[150] T. M. Casey, J. Eneman, A. Crocker, J. White, J. Tessitore, M. Stanely, S. Herlow, J. Y. Bunn, D. Weaver, H. Muss and K. Plaut, "Cancer Associated Fibroblast Stimulated by Transforming Growth Factor Betal (TGFBeta 1) Increase Invasion Rate of Tumor Cells: A Population Study," Breast Cancer Research and Treatment, Vol. 110, No. 1, 2008, pp. 39-49. doi:10.1007/s10549-007-9684-7

[151] A. Noel and J. M. Fordart, "The Role of Stroma in Breast Carcinoma Growth in Vivo," Journal of Mammary Gland Biology and Neoplasia, Vol. 3, No. 2, 1998, pp. 215-225. doi:10.1023/A:1018703208453

[152] R. Kalluri and M. Zeisberg, "Fibroblast in Cancer," Nature Reviews Cancer, Vol. 6, 2006, pp. 392-401. doi:10.1038/nrc1877

[153] J. B. Kim, R. Stein and M. J. O’Hare, "Tumor-Stromal Interactions in Breast Cancer: The Role of Stroma in Tumourigenesis," Tumor Biology, Vol. 26, No. 4, 2005, pp. 173-185. doi:10.1159/000086950

[154] T. D. Tlsty and P. W. Hein, "Know thy Neighbor: Stromal Cells Can Contribute Oncogenic Signals," Current Opinion in Genetics \& Development, Vol. 11, No. 1, 2001, pp. 54-59. doi:10.1016/S0959-437X(00)00156-8

[155] L. Ronnov-Jessen, O. W. Petersen, V. E. Koteliansky and M. J. Bissell, "The Origin of the Myofibroblasts in Breast Cancer. Recapitulation of Tumor Environment in Culture Unravels Diversity and Implicates Converted Fibroblast and Recruited Smooth Muscle Cells," The Journal of Clinical Investigation, Vol. 95, No. 2, 1995, pp. 859-873. doi:10.1172/JCI117736

[156] J. L. Camps, S. Chang, T. C. Hsu, M. R. Freeman, S. Hong, H. E. Zhau, A. C. von Eschenbach and L. W. Chang, "Fibroblast-Mediated Acceleration of Human Epithelial Tumor Growth in Vivo," Proceedings of the National Academy of the Sciences of the United States of America, Vol. 87, No. 1, 1990, pp. 75-79. doi:10.1073/pnas.87.1.75

[157] O. Picard, Y. Rolland and M. F. Poupon, "FibroblastDependent Tumorigenicity of Cells in Nude Mice: Implication for Implantation of Metastases," Cancer Research, Vol. 46, 1986, pp. 3290-3294.

[158] M. Mersmann, A. Schmidt, J. F. Rippman, T. Wuest, B. Brocks, W. J. Rettig, P. Garin-Chesa, K. Pfizenmaier and D. Moosmayer, "Human Antibody Derivative against the Fibroblast Activation Protein for Tumor Stoma Targeting of Carcinomas," International Journal of Cancer, Vol. 92, No. 2, 2001, pp. 240-248. doi:10.1002/1097-0215(200102)9999:9999<::AID-IJC11 70>3.0.CO;2-U
[159] R. Kalluri and M. Zeisberg, "Fibroblast in Cancer," Nature Reviews Cancer, Vol. 6, No. 5, 2006, pp. 392-401. doi:10.1038/nrc1877

[160] L. Ronnov-Jessen, O. W. Petersen and M. J. Bissell, "Cellular Changes Involved in Conversion of Normal to Malignant Breast: Importance of the Stromal Reaction," Physiological Review, Vol. 76, 1996, pp. 69-125.

[161] D. S. Dolberg, R. Hollingsworth, M. Hertle and M. J. Bissell, "Wounding and Its Role in RSV-Mediated Tumor Formation," Science, Vol. 230, No. 4726, 1985, pp. 676678. doi:10.1126/science.2996144

[162] M. A. Sieweke, N. L. Thompson, M. B. Sporn and M. J. Bissell, "Mediation of Wound-Related Rous Sarcoma Virus Tumorigenesis by TGF-Beta," Science, Vol. 248, No. 4963, 1990, pp. 1656-1660. doi:10.1126/science. 2163544

[163] O. W. Petersen, H. L. Nielson, T. Gudjonsson, R. Villadesn, F. Rank, E. Niebuhr, M. J. Bissell and L. Ronnov-Jessen, "Epithelial to Mesenchymal Transition in Human Breast Cancer Can Provide a Nonmalignant Stroma," The American Journal of Pathology, Vol. 162, No. 2, 2003, pp. 391-402. doi:10.1016/S0002-9440(10)63834-5

[164] N. A. Bhowmick, A. Chytil, D. Plieth, A. E. Gorska, N. Dumont, S. Shappell, M. K. Washington, E. G. Neilson and H. L. Moses, "TGF-Beta Signaling in Fibroblast Modulates the Oncogenic Potential of Adjacent Epithelia," Science, Vol. 303, No. 5659, 2004, pp. 848-851. doi:10.1126/science.1090922

[165] C. Kuperwasser, T. Chavarria, M. Wu, G. Magrane, J. W. Gray, L. Carey, A. Richardson and R. A. Weinberg, "Reconstruction of Functionally Normal and Malignant $\mathrm{Hu}-$ man Breast Tissues in Mice," Proceedings of the National Academy of the Sciences of the United States of America, Vol. 101, No. 14, 2004, pp. 4966-4971. doi:10.1073/pnas.0401064101

[166] T. Silzle, G. J. Randolph, M. Krentz and L. A. KunzSchughart, "The Fibroblast: Sentinel Cell and Local Immune Modulator in Tumor Tissue," International Journal of Cancer, Vol. 108, No. 2, 2004, pp. 173-180. doi:10.1002/ijc. 11542

[167] J. A. Wallace, F. Li, G. Leone and M. C. Ostrowski, "PTEN in the Breast Tumor Microenvironment: Modeling Tumor-Stroma Coevoluation," Cancer Research, Vol. 71, No. 4, 2011, pp. 1203-1207. doi:10.1158/0008-5472.CAN-10-3263

[168] G. A. Rabinovich and J. M. Ilarregui, “Conveying Glycan Information into T-Cell Homeostatic Programs: A Challenging Role for Galactin-1 in Inflammatory and Tumor Microenvironment," Immunological Reviews, Vol. 230, No. 1, 2009, pp. 144-159. doi:10.1111/j.1600-065X.2009.00787.x

[169] F. T. Lui and G. A. Rabinovich, "Galectins as Modulators of Tumour Progression," Nature Review Cancer, Vol. 5, No. 1, 2005, pp. 29-41. doi:10.1038/nrc1527

[170]F. A. Van den Brule, D. Waltregny and V. Castronovo, "Increased Expression of Galectins-1 in Carcinoma-Asso- 
ciated Stroma Predicts Poor Outcome in Prostate Carcinoma Patients," The Journal of Pathology, Vol. 193, No. 1, 2001, pp. 80-87.

doi:10.1002/1096-9896(2000)9999:9999<::AID-PATH73 0>3.0.CO;2-2

[171] L. Cindolo, G. Benvenuto, P. Salvatore, R. Pero, G. Salvatore, V. Mirone, D. Preziosi, V. Altieri, C. B. Bruni and L. Chiariotti, "Galectin-1 and Galectins-3 Expression in Human Bladder Transitional-Cell Carcinomas," International Journal of Cancer, Vol. 84, No. 1, 1999, pp. 39-43.

doi:10.1002/(SICI)1097-0215(19990219)84:1<39::AID-I JC8>3.0.CO;2-E

[172] T. Szoke, K. Kayser, J. D. Baumbrakel, I. Trojan, J. Furak, L. Tiszlaviz, A. Horvath, K. Szluha, H. J. Gabius and S. Andre, "Prognostic Significance of Endogenous Adhesion Growth Regulatory Lectins in Lung Cancer," Oncology, Vol. 69, No. 2, 2005, pp. 167-174.

[173] A. Banh, J. Zhang, H. Cao, D. M. Bouley, S. Kwok, C. Kong, A. J. Giaccia, A. C. Koong and Q. T. Le, "Tumor Galectin-1 Mediates Tumor Growth and Metastasis through Regulation of T-Cell Apoptosis," Cancer Research, Vol. 71, No. 13, 2011, pp. 4421-4431. doi:10.1158/0008-5472.CAN-10-4157

[174] W. Rubinstein, M. Alvarez, N. W. Zwirner, M. A. Toscano, J. M. Ilarregui, A. Brovo, J. Mordoh, L. Fainboim, O. L. Podhajcer and G. A. Rabinovich, "Targeted Inhibition of Galectin-1 Gene Expression in Tumor Cells Results in Heightened T Cell-Mediated Rejection; a Potential Mechanism of Tumor-Immune Privilege," Cancer Cell, Vol. 5, No. 3, 2004, pp. 241-251. doi:10.1016/S1535-6108(04)00024-8

[175] V. L. Thijssen, B. Barkan, H. Shoji, I. M. Aries, V. Mathieu, L. Deltour, T. M. Hackeng, R. Kiss, Y. Kloog, F. Poirier and A. W. Griffioen, "Tumor Cell Secrete Galectin1 to Enhance Endothelial Cell Activity," Cancer Research, Vol. 70, No. 15, 2010, pp. 6216-6224. doi:10.1158/0008-5472.CAN-09-4150

[176] W. Rubenstien, M. Alvarez, N. W. Zwirner, M. A. Toscano, J. M. Ilarregui, A. Bravo, J. Mordoh, L. Fainboim, O. L. Podhajcer and G. A. Rabinovich, "Targeted Inhibition of Galectin-1 Gene Expression in Tumor Cells Results Heightened T Cell-Mediated Rejection; A Potential Mechanism of Tumor-Immune Privilege," Cancer Cell, Vol. 5, No. 3, 2004, pp. 241-251. doi:10.1016/S1535-6108(04)00024-8

[177] M. Meissner, T. E. Reichert, M. Kunkel, W. Gooding, T. L. Whiteside, S. Ferrone, and B. Seliger, "Defects in the Human Leukocyte Antigen Class I Antigen Processing Machinery in Head and Neck Squamous Cell Carcinoma: Association with Clinical Outcome," Clinical Cancer Research, Vol. 11, 2005, p. 2552. doi:10.1158/1078-0432.CCR-04-2146

[178] E. M. Shevach, "Fatal Attraction: Tumors Beckon Regulatory T Cells," Nature Medicine, Vol. 10, 2004, pp. 900901. doi: $10.1038 / \mathrm{nm} 0904-900$

[179] C. L. Zindl and D. D. Chaplin, "Tumor Immune Evasion," Science, Vol. 328, No. 5979, 2010, pp. 697-698.

\section{doi:10.1126/science. 1190310}

[180] J. D.Shields, I. C. Kourtis, A. A. Tomei, J. M. Roberts and M. A. Swartz, "Induction of Lymphoidlike Stroma and Immune Escape by Tumors That Express the Chemokines CCL21," Science, Vol. 328, No. 5979, 2010, pp. 749-752. doi:10.1126/science. 1185837

[181] J. D. Shields, M. E. Fleury, C. Young, A. A. Tomei, G. J. Randolph and M. A. Swartz, "Autologous Chemotaxis as a Mechanism of Tumor Cell Homing to Lymphatics via Interstitial Flow and Autocrine CCR7 Signaling," Cancer Cell, Vol. 11, No. 6, 2007, pp. 526-538. doi:10.1016/j.ccr.2007.04.020

[182] G. C. Predergast, "Immune Escape as a Fundamental Trait of Cancer: Focus on IDO," Oncogene, Vol. 27, 2008, pp. 3889-3900. doi:10.1038/onc.2008.35

[183] J. C. Varela, M. Imai, C. Atkinson, R. Ohta, M. Rapisardo and S. Tomlinson, "Modulation of Protective T Cell Immunity by Complement Inhibitor Expression on Tumor Cells," Cancer Research, Vol. 68, 2008, pp. 6734-6742. doi:10.1158/0008-5472.CAN-08-0502

[184] S. Nagaraj and D. I. Gabrilovich, "Tumor Escape Mechanism Governed by Myeloid-Derived Suppressor Cells," Cancer Research, Vol. 68, No. 8, 2008, pp. 2561-2563. doi:10.1158/0008-5472.CAN-07-6229

[185] V. Bronte and P. Zanovello, "Regulation of Immune Responses by L-Arginine Metabolism," Nature Reviews Immunology, Vol. 5, 2005, pp. 641-654. doi:10.1038/nri1668

[186] S. Nagaraj, K. Gupta, V. Pisarev, L. Kinarsky, S. Sherman, L. Kang and D. L. Herber, "Altered Recognition of Antigen Is a Novel Mechanism of $\mathrm{CD}^{+} \mathrm{T}$ Cell Tolerance in Cancer," Nature Medicine, Vol. 13, No. 7, 2007, pp. 828-835. doi:10.1038/nm1609

[187] V. Bronte, T. Kasic, G. Gri, K. Gallana, G. Borsellino, I. Marigo, L. Battistini, M. Iafrate, T. Prayer-Galetti, F. Pagano and A. Viola, "Boosting Antitumor Responses of T Lymphocytes Infiltrating Human Prostate Cancers," The Journal of Experimental Medicine, Vol. 201, No. 8, 2005, pp. 1257-1268. doi:10.1084/jem.20042028

[188] B. Z, Qian and J. W. Pollard, "Macrophage Diversity Enhances Tumor Progression and Metastasis," Cell, Vol. 141, No. 1, 2010, pp. 39-51. doi:10.1016/j.cell.2010.03.014

[189] J. W. Pollard, "Trophic Macrophages in Development and Disease," Nature Reviews Immunology, Vol. 9, 2009, pp. 259-270. doi:10.1038/nri2528

[190] S. Gordon, "Alternative Activation of Macrophages," $N a$ ture Reviews Immunology, Vol. 3, 2003, pp. 23-35. doi:10.1038/nri978

[191] A. Mantovani and A. Sica, "Macrophages, Innate Immunity and Cancer: Balance, Tolerance, and Diversity," Current Opinion in Immunology, Vol. 22, No. 2, 2010, pp. 231-237. doi:10.1016/j.coi.2010.01.009

[192] I. J. Fidler and A. J. Schroit, "Recognition and Destruction of Neoplastic Cells by Activated Macrophage, Discrimination of Altered Self," Biochimica et Biophysica Acta, Vol. 948, No. 2, 1988, pp. 151-173. 
[193] C. Guiducci, A. P. Vicari, S. Sangaletti, G. Trinchieri and M. P. Colombo, "Redirecting in Vivo Elicited Tumor Infiltrating Macrophages and Dendritic Cells towards Tumor Rejection," Cancer Research, Vol. 65, 2005, pp. 3437-3446.

[194] L. S. Ojalvo, W. King, D. Cox and J. W. Pollard, "Highdensity Gene Expression Analysis of Tumor-Associated Macrophages from Mouse Mammary Tumors," The American Journal of Pathology, Vol. 174, No. 3, 2009, pp. 1048-1064. doi:10.2353/ajpath.2009.080676

[195] D. M. Kuang, O. Zhao, C. Peng, J. Xu, J. P. Zhang, C. $\mathrm{Wu}$ and L. Zheng, "Activated Monocytes in Peritumoral Stroma of Hepatocellular Carcinoma Foster Immune Privilege and Disease Progression through PD-L1," The Journal of Experimental Medicine, Vol. 206, No. 6, 2009, pp. 1327-1337. doi:10.1084/jem.20082173

[196] F. Pucci, M. A. Venneri, D. Biziato, A. Nonis, D. Moi, A. Sica, C. Di Serio, L. Naldini and M. De Palma, "A Distinguishing Gene Signature Shared by Tumor-Infiltrating Tie2-Expressing Monocytes Blood 'Resident' Monocytes, and Embryonic Macrophages Suggest Common Functions and Developmental Relationships," Blood, Vol. 114, No. 4, 2009, pp. 901-914.

doi:10.1182/blood-2009-01-200931

[197] A. L. Doedens, C. Stockman, M. P. Rubinstein, D. Liao, N. Zhang, D. G. De Nardo, L. M. Coussens, M. Karin, A. W. Goldrath and R. S. Johnson, "Macrophage Expression of Hypoxia-Inducible Factor-1 Alpha Suppresses T-Cell Function and Promotes Tumor Progression," Cancer Research, Vol. 70, No. 19, 2010, pp. 7465-7475. doi:10.1158/0008-5472.CAN-10-1439

[198] N. Takeda, E. L. O’Dea, A. Doedens, J. W. Kim, A. Widemann, C. Stockmann, M. Asagiri, M. C. Simon, A. Hoffmann and R. S. Johnson, "Differential Activation and Antagonistic Function of HIF-\{Alpha\} Isoforms in Macrophages Are Essential for NO Homeostasis," Genes \& Development, Vol. 24, 2010, pp. 491-201. doi:10.1101/gad.1881410

[199] S. Sakaguchi, T. Yamaguchi, T. Nomura and M. Ono, "Regulatory T Cell and Immune Tolerance," Cell, Vol. 133, No. 5, 2008, pp. 775-787. doi:10.1016/j.cell.2008.05.009

[200] A. Laurence, C. M. Tato, T. S. Davidson, Y. Kanno, Z. Chen, Z. Yoo, R. B. Blank, F. Meylan, R. Siegel, L. Hennighausen, E. M. Shevach and J. J. O'shea, "Interleukin-2 Signaling via STAT5 Constrains T Helper 17 Cell Generation," Immunity, Vol. 26, No. 3, 2007, pp. 371-381. doi:10.1016/j.immuni.2007.02.009

[201] A. Y. Rudensky, M. Gavin and Y. Zheng, "FOXP3 and NFAT: Partners in Tolerance," Cell, Vol. 126, No. 2, 2006, pp. 253-256. doi:10.1016/j.cell.2006.07.005

[202] Y. Wu, M. Borde, V. Heissmeyer, M. Feuerer, A. D. Lapan, J. C. Stroud, D. L. Bates, L. Guo, A. Han, S. F. Ziegler, D. Mathis, C. Benoist, L. Chen and A. Rao, "FOXP3 Controls Regulatory T Cell Function through Cooperation with NFAT," Cell, Vol. 126, No. 3, 2006, pp. 375-387. doi:10.1016/j.cell.2006.05.042

[203] M. Mahic, S. Yaqub, C. C. Johansson, K. Tasken and E.
M. Aandahl, "FOXP3+CD4+CD25+ Adaptive Regulatory T Cells Express Cyclooxygenase-2 and Suppresses Effector T Cells by a Prostaglandin E2-Dependent Mechanism," The Journal of Immunology, Vol. 177, No. 2, 2006, pp. 246-254.

[204] A. M. Thorton and E. M. Shevach, "Suppressor Effector Function of CD4+CD25+ Immunoregulatory T Cells Is Antigenic Nonspecific," The Journal of Immunology, Vol. 164, No. 1, 2000, pp. 183-190.

[205] P. McGuirk, C. McCann and K. H. Mills, "PathogenSpecific T Regulatory 1 Cells Induced in the Respiratory Tract by a Bacterial Molecule That Stimulates Interleukin 10 Production by Dendritic Cells: A Novel Strategy for Evasion of Protective T Helper Type 1 Responses by Bordetella Pertussis," The Journal of Experimental Medicine, Vol. 195, No. 2, 2002, pp. 221-231. doi:10.1084/jem.20011288

[206] S. Yamagiwa, J. P. Gray, S. Hashimoto and A. Horwitz, "A Role for TGF-Beta in the Generation and Expansion of CD4+CD25+ Regulatory T Cells from Human Peripheral Blood," The Journal of Immunology, Vol. 166, 2001, pp. 7282-7289.

[207] K. M. Torgerson, T. Vang, H. Abrahamsen, S. Yaqub, V. Horejsi, B. Schraven, B. Rolstad, T. Mustelin and K. Tasken, "Release from Tonic Inhibition of T Cell Activation through Transient Displacement of C-Terminal Src Kinase (Csk) from Lipid Rafts," The Journal of Biological Chemistry, Vol. 276, 2001, pp. 29313-29318. doi:10.1074/jbc.C100014200

[208] T. Vang, K. M. Torgersen, V. Sundvold, M. Saxena, F. O. Levy, B. S. Skalhegg, V. Hansson, T. Mustelin and K. Tasken, "Activation of the COOH-Terminal Src Kinase (Csk) by cAMP-Dependent Protein Kinase Inhibits Signaling through the T Cell Receptor," The Journal of Experimental Medicine, Vol. 193, No. 4, 2001, pp. 497-507. doi:10.1084/jem.193.4.497

[209] T. Vang, H. Abrahamsen, S. Myklebust, V. Horejsi and K. Tasken, "Combined Spatial and Enzymatic Regulation of Csk by cAMP and Protein Kinase a Inhibits T Cell Receptor Signaling," The Journal of Biological Chemistry, Vol. 278, 2003, pp. 17597-17600. doi: 10.1074/jbc.C300077200

[210] H. Lu, "FOXP3 Expression and Prognosis: Role of Both the Tumor and T Cells," Journal of Clinical Oncology, Vol. 27, No. 11, 2009, pp. 1735-1736. doi:10.1200/JCO.2008.20.0675

[211] T. J. Curiel, G. Coukos, L. Zou, X. Alverez, P. Cheng, P. Mottram, M. Evdemon-Hogan, J. R. Conejo-Garcia, L. Zhang, M. Burow, Y. Zhu, S. Wei, I. Kryczek, B. Daniel, A. Gordon, L. Myers, A. Lackner, M. L. Disis, K. L. Kroutson, L. Chen and W. Zou, "Specific Recruitment of Regulatory $\mathrm{T}$ Cells in Ovarian Carcinoma Fosters Immune Privilege and Predicts Reduced Survival," Nature Medicine, Vol. 10, 2004, pp. 942-949. doi:10.1038/nm1093

[212] G. J. Bates, S. B. Fox, C. Han, R. D. Leek, J. F. Garcia, A. L. Harris and A. H. Banham, "Quantification of Regulatory $\mathrm{T}$ Cells Enables the Identification of High-Risk 
Breast Cancer Patients and Those at Risk of Late Relapse," The Journal of Clinical Oncology, Vol. 24, No. 34, 2006, pp. 5373-5380. doi:10.1200/JCO.2006.05.9584

[213] S. Ladoire, L. Arnould, L. Apetoh, B. Coudert, F. Martin, B. Chauffert, P. Fumoleau and F. Ghiringhelli, "Pathologic Complete Response to Neoadjuvant Chemotherapy of Breast Carcinoma Is Associated with the Disappearance of Tumor-Infiltrating Foxp $3^{+}$Regulatory T Cells," Clinical Cancer Research, Vol. 14, 2008, pp. 2413-2420. doi:10.1158/1078-0432.CCR-07-4491

[214] S. Nair, D. Boczkowski, M. Fassnacht, D. Pisetsky and E. Gilboa, "Vaccination against the Forkhead Family Transcription Factor Foxp3 Enhances Tumor Immunity," Cancer Research, Vol. 67, 2007, pp. 371-380. doi:10.1158/0008-5472.CAN-06-2903

[215] A. Merlo, P. Casalini, M. L. Carcangiu, C. Malvenatno, T. Triulzi, S. Menard, E. Tagliabue and A. Balsari, "FOXP3 Expression and Overall Survival in Breast Cancer," The Journal of Clinical Oncology, Vol. 27, No. 11, 2009, pp. 1746-1752. doi:10.1200/JCO.2008.17.9036

[216] L. Stauss, C. Bergmann, M. Szczepanski, W. Gooding, J. T. Johnson and T. L. Whiteside, "A Unique Subset of CD4+CD25highFoxP3+ T Cells Secreting Interleukin-10 and Transforming Growth Factor-Beta1 Mediates Suppression in the Tumor Microenvironment," Clinical Cancer Research, Vol. 13, 2007, pp. 4345-4354. doi:10.1158/1078-0432.CCR-07-0472

[217] N. Larmonier, M. Marron, Y. Zeng, J. Cantrell, A. Romanoski, M. Sepassi, S. Thompson, X. Chen, S. Andreasky and E. Katsanis, "Tumor-Derived CD4(+)CD25(+) Regulatory T Cell Suppression of Dendritic Cell Function Involves TGF-Beta and IL-10," Cancer Immunology, Immunotherapy, Vol. 56, No. 1, 2007, pp. 48-59. doi:10.1007/s00262-006-0160-8

[218] F. Liu, R. Lang, J. Zhao, X. Zhang, G. A. Pringle, Y. Fan, D. Yin, F. Gu, Z. Yao and L. Fu, "CD8+ Cytotoxic T Cell and FOXP3+ Regulatory T Cell Infiltration in Relation to Breast Cancer Survival and Molecular Subtypes," Breast Cancer Research and Treatment, Vol. 130, No. 2, 2011, pp. 645-655. doi:10.1007/s10549-011-1647-3

[219] P. Zhang, A. L. Cote, V. C. de Vries, E. J. Ushewood and M. J. Turk, "Induction of Postsurgical Tumor Immunity and T-Cell Memory by a Poorly Immunogenic Tumor," Cancer Research, Vol. 67, 2007, pp. 6468-6476. doi:10.1158/0008-5472.CAN-07-1264

[220] A. L. Cote, E. J. Usherwood and M. J. Turk, "Tumor-Specific T-Cell Memory: Clearing the Regulatory T-Cell Hurdle," Cancer Research, Vol. 68, No. 6, 2008, pp. 1614-1617. doi:10.1158/0008-5472.CAN-07-6012

[221] H. Tanaka, J. Tanaka, J. Kjaergaad and S. Shu, "Depletion of CD4+ CD25+ Regulatory Cells Augments the Generation of Specific Immune T Cells in Tumor-Draining Lymph Nodes," Journal of Immunotherapy, Vol. 25, No. 3, 2002, pp. 207-217. doi:10.1097/00002371-200205000-00003

[222] S. J. O’Day, O. Hamid and W. J. Urba, "Targeting Cytotoxic T-Lymphocyte Antigen-4 (CTLA-4): A Novel Strategy for the Treatment of Melanoma and other Ma- lignancies," Cancer, Vol. 110, No. 12, 2007, pp. 26142627.

[223] M. A. Morse, “Technology EVALUATION; ipilimumab, MEDAREX/Bristol-Myers Squibb," Current Opinion in Molecular Therapeutics, Vol. 7, No. 6, 2005, pp. 588597.

[224] M. Terme, E. Ullrich, L. Aymeric, K. Meinhardt, M. Desbois, N. Delahaye, S. Viaud, B. Ryffel, H. Yagita, G. Kaplanski, A. Prevost-Blondel, M. Kato, J. L. Schultze, E. Tartour, G. Kroemer, N. Chaput and L. Zitvogel, "IL-18 Induces PD-1-Dependent Immunosuppression in Cancer," Cancer Research, Vol. 71, No. 16, 2011, pp. 5393-5399. doi:10.1158/0008-5472.CAN-11-0993

[225] W. Zou, "Immunosuppressive Networks in the Tumor Environment and Their Therapeutic Relevance," Nature Reviews Cancer, Vol. 5, 2005, pp. 263-274. doi:10.1038/nrc1586

[226] M. W. Teng, D. M. Andrews, N. McLaughlin, B. von Schedit, S. F. Ngiow, A. Moller, G. R. Hill, Y. Iwakura, M. Oft and M. J. Smyth, "IL-23 Suppresses Innate Immune Response Independently of IL-17A during Carcinogenesis and Metastasis," Proceedings of the National Academy of the Sciences of the United States of America, Vol. 107, 2010, pp. 8328-8333. doi:10.1073/pnas.1003251107

[227] E. Mamessier, A. Sylvain, F. Bertucci, R. Castellano, P. Finetti, G. Houvenaeghel, E. Charaffe-Jaufret, D. Birnbaum, A. Moretta and D. Olive, "Human Breast Tumor Cells Induce Self Tolerance Mechanisms to Avoid NKG2D-Mediated and DNAM Mediated NK Cell Recognition," Cancer Research, Vol. 71, No. 21, 2011, pp. 6621-6632. doi:10.1158/0008-5472.CAN-11-0792

[228] M. Madhavan, P. Srinivas, E. Abraham, I. Akmed, N. R. Vijayalekshmi and P. Balaram, "Downregulation of endothelial Adhesion Molecules in Node Positive Breast Cancer: Possible Failure of Host Defense Mechanism," Pathology \& Oncology Research, Vol. 8, No. 2, 2002, pp. 125-128. doi:10.1007/BF03033721

[229] L. M. Stoolman, “Adhesion Molecules Controlling Lymphocyte Migration," Cell, Vol. 56, No. 6, 1989, pp. 907910. doi:10.1016/0092-8674(89)90620-X

[230] L. Osborn, C. Hession, R. Tizard, C. Vassallo, S. Luhowskj, G. Chi-Rosso and R. Lobb, "Direct Expression Cloning of Vascular Cell Adhesion Molecule 1, a Cytokine-Induced Endothelial Protein That Binds to Lymphocytes," Cell, Vol. 59, No. 6, 1989, pp. 1203-1211. doi:10.1016/0092-8674(89)90775-7

[231] S. Delfortne, S. Pinte, U. Mattot, C. Samson, G. Villain, B. Caetano, G. Lauridant-Philippin, M. C. Baranzelli, J. Bonneterre, F. Trottein, C. Faveeuw and F. Soncin, "EgfI7 Promotes Tumor Escape from Immunity by Repressing Endothelial Cell Activation," Cancer Research, Vol. 71, No. 23, 2011, pp. 7176-7186. doi:10.1158/0008-5472.CAN-11-1301

[232] D. Jin, J. Fan, L. Wang, L. F. Thompson, A. Liu, B. J. Daniel, T. Shin, T. J. Curiel and B. Zhang, "CD73 on Tumor Cells Impairs Antitumor T-Cell Responses: A Novel Mechanism of Tumor-Induced Immune Suppres- 
sion," Cancer Research, Vol. 70, No. 6, 2010, pp. 22452255. doi:10.1158/0008-5472.CAN-09-3109

[233] K. M. Dwyer, S. Deaglio, W. Gao, D. Friedman, T. B. Strom and S. C. Robson, "CD39 and Control of Cellular Immune Responses," Purinergic Signal, Vol. 3, No. 1-2, 2007, pp. 171-180. doi:10.1007/s11302-006-9050-y

[234] S. Huang, S. Apasov, M. Koshiba and M. Sitkovsky, "Role of A2a Extracellular Adenosine Receptor-Mediated Signaling in Adenosine-Mediated Inhibition of T-Cell Activation and Expansion," Blood, Vol. 90, No. 4, 1997, pp. 1600-1610.

[235] S. Deaglio, K. M. Dwyer, W. Gao, D. Friedman, A. Usheva, A. Erat, J. F. Chen, K. Ejyoji, J. Linden, M. Oukka, V. K. Kuchroo, T. B. Strom and S. C. Robson, "Adenosine Generation Catalyzed by CD39 and CD73 Expressed on Regulatory T Cells Mediates Immune Suppression," Journal of Experimental Medicine, Vol. 204, No. 6, 2007, pp. 1257-1265. doi:10.1084/jem.20062512

[236] O. Canbolat, I. Durak, R. Cetin, M. Kavutru, S. Demirci and S. Ozturk, "Activites of Adenosine Deaminase, 5'Nucleotidase, Guanase, and Cytidine Deaminase Enzymes in Cancerous and Non-Cancerous Human Breast Tissues," Breast Cancer Research and Treatment, Vol. 37, No. 2, 1996, pp. 189-193. doi:10.1007/BF01806500

[237] L. Wang, X. Zhou, T. Zhou, D. Ma, S. Chen, X. Zhi, L. Yin, Z. Shao, Z. Ou and P. Zhou, "Ecto-5'-Nucleotidase Promoter Invasion, Migration and Adhesion of Human Breast Cancer Cells," Journal of Cancer Research and Clinical Oncology, Vol. 134, No. 3, 2008, pp. 365-372. doi:10.1007/s00432-007-0292-Z

[238] J. Spychala, E. Lazarowski, A. Ostapkowicz, L. H. Ayscue, A. Jin and B. S. Mitchell, "Role of Estrogen Receptor in the Regulation of Ecto-5'-Nucelotidase and Adenosine in Breast Cancer," Clinical Cancer Research, Vol. 10, 2004, pp. 708-717. doi:10.1158/1078-0432.CCR-0811-03

[239] A. Ohta, E. Gorlick, S. J. Prasad, F. Ronchese, D. Lukashev, M. K. Wong, X. Huang, S. Caldwell, K. Liu, P. Smith, J. F. Chen, E. K. Jackson, S. Apason, S. Abrams and M. Sitkovsky, "A2A Adenosine Receptor Protects Tumors from Antitumor T Cells," Proceedings of the National Academy of the Sciences of the United States of America, Vol. 103, No. 35, 2006, pp. 13132-13137. doi: $10.1073 /$ pnas.0605251103

[240] R. Ros and L. A. Shermon, "CD4+ T-Cell Help in the Tumor Milieu Is Required for Recruitment and Cytolytic Function of CD8+ T Lymphocytes," Cancer Research, Vol. 70, No. 21, 2010, pp. 78368-78377.

[241] R. Kim, M. Emi, K. Tanabe and K. Arihiro, "TumorDriven Evolution of Immunosuppressive Networks during Malignant Progression," Cancer Research, Vol. 66, No. 11, 2006, pp. 5527-5536. doi:10.1158/0008-5472.CAN-05-4128

[242] K. Kessenbrock, V. Plaks and Z. Werb, "Matrix Metalloproteinases: Regulators of the Tumor Microenvironment," Cell, Vol. 141, No. 1, 2010, pp. 52-67. doi:10.1016/j.cell.2010.03.015
[243] J. Gross and C. Lampiere, "Collagenolytic Activity in Amphibian Tissues: A Tissue Culture Assay," Proceedings of the National Academy of the Sciences of the United States of America, Vol. 48, No. 6, 1962, pp. 10141022. doi:10.1073/pnas.48.6.1014

[244] M. Sternlicht and Z. Werb, "How Matrix Metalloproteinases Regulate Cell Behavior," Annual Review of Cell and Developmental Biology, Vol. 17, 2001, pp. 463-516. doi:10.1146/annurev.cellbio.17.1.463

[245] D. Edwards, M. Handsley and C. Pennington, "The ADAM Metalloproteinases," Molecular Aspects of Medicine, Vol. 29, No. 5, 2008, pp. 258-289. doi:10.1016/j.mam.2008.08.001

[246] E. Deryugina and J. Quigley, "Matrix Metalloproteinases and Tumor Metastasis," Cancer and Metastasis Reviews, Vol. 25, No. 1, 2006, pp. 9-34. doi:10.1007/s10555-006-7886-9

[247] M. Egeblad and Z. Werb, "New Functions for Matrix Metalloproteinases in Cancer Progression," Nature Reviews Cancer, Vol. 2, 2002, pp. 161-174. doi:10.1038/nrc745

[248] P. Rupp, R. Visconti, A. Czirok, D. Cheresh and C. Little, "Matrix Metalloproteinase 2-Integrin Alpha (v) Beta3 Binding Is Required for Mesenchymal Cell Invasive Activity but Not Epithelial Locomotion: A Computational Time-Lapse Study," Molecular Biology of the Cell, Vol. 19, No. 12, 2008, pp. 5529-5540. doi:10.1091/mbc.E07-05-0480

[249] P. Friedl and K. Wolf, "Tube Travel: The Role of Proteases in Individual and Collective Cancer Cell Invasion," Cancer Research, Vol. 68, 2008, pp. 7247-7249. doi:10.1158/0008-5472.CAN-08-0784

[250] F. Sabeh, I. Ota, K. Holmbeck, H. Birkedal-Hansen, P. Soloway, M. Balbin, C. Lopez-Otin, S. Shapiro, M. Inada, S. Krane, E. Allen, D. Chung and S. Weiss. , "Tumor Cell Traffic through the Extracellular Matrix Is Controlled by the Membrane-Anchored Collagenase MT1-MMP," Joural of Cell Biology, Vol. 167, No. 4, 2004, pp. 769-781. doi: $10.1083 /$ jcb. 200408028

[251] K. Wolf, Y. Wu, Y. Liu, J. Geiger, E. Tam, C. Overall, M. Stack and P. Friedl, "Multi-Step Pericellular Proteolysis Controls the Transition from Individual to Collective Cancer Cell Invasion," Nature Cell Biology, Vol. 9, 2007, pp. 893-904. doi:10.1038/ncb1616

[252] D. Butcher, T. Alliston and V. Weaver, "A Tense Situation: Forcing Tumour Progression," Nature Reviews Cancer, Vol. 9, 2009, pp. 108-122. doi:10.1038/nrc2544

[253] L. Lotta, K. Tyggvason, S. Garbisa, I. Hart, C. Foltz and S. Shafie, "Metastatic Potential Correlates with Enzymatic Degradation of Basement Membrane Collagen," Nature, Vol. 284, 1980, pp. 67-68. doi:10.1038/284067a0

[254] L. Coussens, B. Fingleton and L. Matrisian, "Matrix Metalloproteinase Inhibitors and Cancer: Trials and Tribulations," Science, Vol. 295, No. 5564, 2002, pp. 2387-2392. doi:10.1126/science. 1067100

[255] J. Massague, "TGFbeta in Cancer," Cell, Vol. 134, No. 2, 2008, pp. 215-230. doi:10.1016/j.cell.2008.07.001 
[256] N. Hynes and H. Lane, "ERBB Receptors and Cancer: The Complexity of Targeted Inhibitors," Nature Reviews Cancer, Vol. 5, 2005, pp. 341-354. doi:10.1038/nrc1609

[257] K. Cowen Dahl, J. Symowicz, Y. Ning, E. Gutierrez, D. Fishman, B. Adley, M. Stack and L. Hudson, "Matrix Metalloproteinase 9 Is a Mediator of Epidermal Growth Factor-Dependent E-Cadherin Loss in Ovarian Carcinoma Cells," Cancer Research, Vol. 68, 2008, pp. 46064613. doi:10.1158/0008-5472.CAN-07-5046

[258] N. Mitsiades, W. Yu, V. Poulaki, M. Tsokos and I. Stamenkovic, "Matrix Metalloproteinase-7-Mediated Cleavage of Fas Ligand Protects Tumor Cells from Chemotherapeutic Drug Cytotoxicity," Cancer Research, Vol. 61, No. 2, 2001, pp. 577-581.

[259] M. Schulte, K. Reiss, M. Lettau, T. Maretzky, A. Ludwig, D. Hartmann, B. de Strooper, O. Janssen and P. Saftig, "ADAM10 Regulates FasL Cell Surface Expression and Modulates FasL-Induced Cytotoxicity and Activation-Induced Cell Death," Cell Death \& Differentiation, Vol. 14, No. 5, 2007, pp. 1040-1049.

[260] I. Waldhauer, D. Goehlsdorf, F. Gieseke, T. Weinschenk, M. Wittenbrink, A. Ludwig, S. Stevanovic, H. Rammensee and A. Steinle, "Tumor Associated MICA Is Shed by ADAM Proteases," Cancer Research, Vol. 68, 2008, pp.
6368-6376. doi:10.1158/0008-5472.CAN-07-6768

[261] G. Ahu and J. Brown, "Matrix metalloproteinase-9 Is Required for Tumor Vasculogenesis but Not for Angiogenesis: Role of Bone Marrow-Derived Myelomonocytic Cells," Cancer Cell, Vol. 13, No. 3, 2008, pp. 193-205. doi:10.1016/j.ccr.2007.11.032

[262] E. Nakamuri, K. Koizumi, M. Kobayashi and I. Saiki, "Inhibition of Lymphangiogenesis-Related Properties of Murine Lymphatic Endothelial Cells and Lymph Node Metastasis of Lung Cancer by the Matrix Metalloproteinase Inhibitor MMI270," Cancer Sciences, Vol. 95, No. 1, 2004, pp. 25-31. doi:10.1111/j.1349-7006.2004.tb03166.x

[263] R. Kaplan, R. Riba, S. Zacharoulis, A. Bramley, L. Vincent, C. Costa, D. MacDonald, D. Jin, K. Shido, S. Kerns, Z. Zhenping, D. Hicklin, Y. Wu, J. Port, N. Altorki, E. Port, D. Ruggero, S. Schmelkov, K. Jensen, S. Rafi and D. Lyden, "VEGFR1-Positive Haematopoietic Bone Marrow Progenitors Initiate the Pre-Metastatic Nice," Nature, Vol. 438, 2005, pp. 820-827. doi:10.1038/nature04186

[264] W. Lin and M. Karin, "A Cytokine-Mediated Link between Innate Immunity, Inflammation, and Cancer," Journal of Clinical Investigation, Vol. 117, No. 5, 2007, pp. 1175-1183. doi:10.1172/JCI31537 